\title{
The impact of volcanic eruptions of different magnitude on stratospheric water vapor in the tropics
}

\author{
Clarissa Alicia Kroll ${ }^{1,2}$, Sally Dacie ${ }^{1,2}$, Alon Azoulay ${ }^{1, a}$, Hauke Schmidt ${ }^{1}$, and Claudia Timmreck ${ }^{1}$ \\ ${ }^{1}$ Atmosphere in the Earth System, Max Planck Institute for Meteorology, Hamburg, Germany \\ ${ }^{2}$ International Max Planck Research School on Earth System Modelling (IMPRS-ESM), Hamburg, Germany \\ ${ }^{a}$ now at: Remote Sensing Technology Institute (IMF), German Aerospace Center (DLR), Oberpfaffenhofen, Germany
}

Correspondence: Clarissa Alicia Kroll (clarissa.kroll@mpimet.mpg.de)

Received: 20 November 2020 - Discussion started: 30 November 2020

Revised: 1 March 2021 - Accepted: 10 March 2021 - Published: 1 May 2021

\begin{abstract}
Increasing the temperature of the tropical coldpoint region through heating by volcanic aerosols results in increases in the entry value of stratospheric water vapor (SWV) and subsequent changes in the atmospheric energy ${ }_{5}$ budget. We analyze tropical volcanic eruptions of different strengths with sulfur (S) injections ranging from $2.5 \mathrm{Tg} \mathrm{S}$ up to $40 \mathrm{Tg} \mathrm{S}$ using EVAens, the 100-member ensemble of the Max Planck Institute - Earth System Model in its lowresolution configuration (MPI-ESM-LR) with artificial vol10 canic forcing generated by the Easy Volcanic Aerosol (EVA) tool. Significant increases in SWV are found for the mean over all ensemble members from $2.5 \mathrm{Tg} \mathrm{S}$ onward ranging between $[5,160] \%$. However, for single ensemble members, the standard deviation between the control run mem15 bers $(0 \mathrm{Tg} \mathrm{S})$ is larger than SWV increase of single ensemble members for eruption strengths up to $20 \mathrm{Tg} \mathrm{S}$. A historical simulation using observation-based forcing files of the Mt. Pinatubo eruption, which was estimated to have emitted $(7.5 \pm 2.5) \mathrm{Tg} \mathrm{S}$, returns SWV increases slightly higher ${ }_{20}$ than the $10 \mathrm{Tg} \mathrm{S}$ EVAens simulations due to differences in the aerosol profile shape. An additional amplification of the tape recorder signal is also apparent, which is not present in the $10 \mathrm{Tg} \mathrm{S}$ run. These differences underline that it is not only the eruption volume but also the aerosol layer shape 25 and location with respect to the cold point that have to be considered for post-eruption SWV increases. The additional tropical clear-sky SWV forcing for the different eruption strengths amounts to $[0.02,0.65] \mathrm{W} \mathrm{m}^{-2}$, ranging between $[2.5,4] \%$ of the aerosol radiative forcing in the $10 \mathrm{Tg} \mathrm{S}$ sce30 nario. The monthly cold-point temperature increases leading to the SWV increase are not linear with respect to aerosol
\end{abstract}

optical depth (AOD) nor is the corresponding SWV forcing, among others, due to hysteresis effects, seasonal dependencies, aerosol profile heights and feedbacks. However, knowledge of the cold-point temperature increase allows for an estimation of SWV increases of $12 \%$ per Kelvin increase in mean cold-point temperature. For yearly averages, power functions are fitted to the cold-point warming and SWV forcing with increasing AOD.

\section{Introduction}

It has been established that the entry of water vapor into the stratosphere is largely controlled by the temperature of the tropical tropopause (e.g., Brewer, 1949; Mote et al., 1996; Fueglistaler et al., 2009; Dessler et al., 2014). Following up on the discussion of the long-term increasing trend in stratospheric water vapor (SWV) observed during the 1980s and 1990 s, it was proposed that volcanic eruptions could be influencing the SWV budget (e.g., Rosenlof et al., 2001; Joshi and Shine, 2003). Mainly, two processes are considered: the direct volcanic injection from the volcanic plume and an indirect volcanic mechanism due to an increase of the tropopause temperature, referred to hereafter as the indirect volcanic pathway. The increased SWV levels may remain in the stratosphere for more than 5 years (Hall and Waugh, 1997), even though the volcanic aerosols sediment out of the stratosphere within 1-3 years (Robock, 2000). However, the magnitude of the SWV increase and the contribution from the different entry mechanisms are still unclear. 
In total, $80 \%$ of the eruption material is water vapor (Coffey, 1996), which could be directly injected into the stratosphere during an eruption event. But although the SWV originating form the direct injection can be detected shortly af${ }_{5}$ ter the eruption event, it is a singular event. The corresponding elevated SWV levels are spread in the stratosphere and are not distinguishable from the background SWV anymore. Satellite evidence for the direct injection events exist. It is discussed briefly by Schwartz et al. (2013) and in depth by ${ }_{10}$ Sioris et al. (2016a, b). Based on a model study, Joshi and Jones (2009) hypothesized that the environment surrounding the plume can also have a significant impact on the amount of SWV injected directly.

This study will focus on the indirect volcanic entry mech15 anism. In contrast to the direct entry, it can act for months or even years after volcanic eruptions since it depends on the heating caused by the aerosol layer in the stratosphere and not on the eruption event itself. This indirect volcanic entry is caused by the terrestrial longwave and near-IR solar heating ${ }_{20}$ by the volcanic aerosol layer which leads to increased coldpoint temperatures. Consequently, the saturation water vapor pressure at the cold point is increased, thereby reducing the loss of WV due to ice formation and fallout. This mechanism enhances the entry of WV into the stratosphere. In an early 25 idealized study, Joshi and Shine (2003) underlined the importance of the aerosol profile and corresponding heating in the tropopause region. Despite the mechanisms being known, its analysis is still complicated, as internal variability and scarcity of observations have made it difficult to observe it in so practice. Additionally, even if SWV increases are recorded, the data usage might be discouraged, as was the case for Mt. Pinatubo by the Stratospheric Aerosol and Gas Experiment II (SAGE II) because discrepancies between different satellites could not be satisfactorily explained (Fueglistaler ${ }_{35}$ et al., 2013). The scarcity of observational data is also reflected in the quality of the available reanalysis products for SWV, the usage of which in general is discouraged in some papers (e.g., Davis et al., 2017) and which sometimes do not implicitly account for the volcanic forcing at all (Diallo et al., ${ }_{40}$ 2017; Tao et al., 2019). The latter problem was also indicated by Löffler et al. (2016) when discussing SWV increases simulated for the eruption of Mt. Pinatubo. Nevertheless, by performing a regression analysis using a trajectory model fed by reanalysis data, Dessler et al. (2014) identified a SWV peak ${ }_{45}$ partially overlapping with the aerosol optical depth (AOD) signal of Mt. Pinatubo. As the SWV increase occurred before the eruption and AOD increase, the question remained if the peak in the residual might instead be caused by another source of variability. Another possible issue in their analy${ }_{50}$ sis is that some of the effects modeled by the regressors are themselves influenced by volcanic eruptions, which may lead to the volcanic signal being attributed to a different source. An example are the increases of the Brewer-Dobson circulation (BDC), which, in the case of a volcanic eruption, can ${ }_{55}$ be partially caused by the heating due to the aerosol layer.
Tao et al. (2019) also undertook an indirect quantification of the SWV increase after volcanic eruptions via another regression analysis, explicitly accounting for volcanic source terms. They found a clear volcanic signal in the expected time frame, but the magnitude of the SWV increase differed strongly between the individual reanalysis data sources.

After entering the stratosphere, the additional SWV affects both stratospheric chemistry with respect to ozone loss (Robrecht et al., 2019; Rosenlof, 2018; Tian et al., 2009) and $\mathrm{SO}_{2}$ oxidation (Bekki, 1995; LeGrande et al., 2016), as well as the 65 radiative budget of the entire atmosphere (Solomon et al., 2010). Despite the forcing originating from the additional SWV often being mentioned as a motivation for studies, few studies exist on the forcing effect of the SWV increase after volcanic eruptions. Independent of volcanic eruptions, 70 Forster and Shine (2002) analyzed the forcing impact of SWV changes in an artificial SWV profile. In a study focusing on the Mt. Pinatubo eruption, Joshi and Shine (2003) calculated the additional global forcing originating from the post-eruption SWV increase. As this was a side study of their paper, they did not investigate the temporal evolution nor the impact of different eruption strengths. In a study on the direct injection, Joshi and Jones (2009) quantified the longwave component of the SWV forcing indirectly, but their setup did not allow for a quantification of the additional contribution of 8 the indirect volcanic pathway. Most recently, Krishnamohan et al. (2019) attributed changes in their top-of-atmosphere (TOA) imbalances for different geoengineering scenarios to a large influence of SWV. However, they did not separate the contributions of aerosol forcing and SWV.

So far, the questions remain open as to what the critical magnitude is for an eruption to have a significant impact on SWV content, what the radiative consequences of the SWV increase are, and if these effects can be predicted based on eruption magnitude or AOD. In this study, we therefore in- 9 vestigate the changes in stratospheric water vapor originating from the indirect volcanic pathway using a large ensemble of coupled climate model simulations with 100 ensemble members each for five eruption strengths described by changing amount of stratospheric sulfur and a control run, 95 called EVAens (Azoulay et al., 2021). The idealized setup using forcing files generated with the Easy Volcanic Aerosol tool (EVA) offers the unique opportunity of a direct comparison between the different eruption strengths, since the date and location of the eruptions are identical and all en- 100 sembles have the same set of starting conditions. By comparison with the control run, a direct quantification of the SWV increase is possible. The large ensemble size allows us to perform an analysis of the sensitivity of the increase in stratospheric water vapor to the eruption strength along with 105 its statistical significance. The critical eruption strengths that cause stratospheric water vapor perturbations beyond the internal variability of the model are identified when analyzing the individual ensemble members. 


\section{Methods}

\subsection{The EVAens ensemble and the GE historical simulations}

This study is based on large ensemble simulations covering 5 the time frame of January 1991 to December 1993 using two different volcanic forcing data sets: EVAens (Azoulay et al., 2021) and a subset of the Max Planck Institute Grand Ensemble (MPI-GE) historical simulations (Maher et al., 2019). Both ensemble simulations are performed with the Max ${ }_{10}$ Planck Institute - Earth System Model in its low-resolution configuration (MPI-ESM-LR) (version MPI-ESM 1.1.00p2). We apply an intermediate model version between the Coupled Model Intercomparison Project phase 5 (CMIP5) version (Giorgetta et al., 2013) and the CMIP6 version (Maurit15 sen et al., 2019) of MPI-ESM, with a behavior closer to the CMIP6 version. MPI-ESM itself is a coupled model including the atmosphere component - ECHAM (version echam6.3.01p3; Stevens and Bony, 2013), the land component - the Jena Scheme for Biosphere Atmosphere Coupling in Ham20 burg (JSBACH; version jsbach-3.00; Reick et al., 2013; Schneck et al., 2013), the ocean component - the MPI Ocean Model (MPIOM; version mpiom-1.6.1p1; Marsland et al., 2003; Jungclaus et al., 2013) and the biogeochemistry component - the Hamburg ocean carbon cycle model (HAMOCC 25 version 5.2; Ilyina et al., 2013). In the model setup, the atmosphere is run in a T63L47 configuration corresponding to a horizontal resolution of about $1.9^{\circ}$ with 47 pressure levels up to $0.01 \mathrm{hPa}$. The influence of the sponge layer in the uppermost model layer reaches down to a height of $65 \mathrm{~km}$ ${ }_{30}$ with continuously decreasing impact. As MPI-ESM-LR does not include interactive atmospheric chemistry or aerosols, the volcanic aerosols are prescribed by the monthly zonal mean values of their optical properties - the extinction, single scattering albedo and asymmetry factor - in 16 long${ }_{35}$ wave and 14 shortwave bands. During the simulation, these monthly aerosol properties are interpolated linearly in time. In the MPI-GE historical simulations, the optical properties of the volcanic aerosols are prescribed with an updated version of the Pinatubo aerosol data set (PADS) (Stenchikov 40 et al., 1998; Driscoll et al., 2012; Schmidt et al., 2013). The Mt. Pinatubo eruption in June 1991 lies in the investigated time frame.

In EVAens, the setup of the MPI-GE historical simulations was kept, changing only the stratospheric aerosols' repre45 sentation. The respective forcing files were generated using the Easy Volcanic Aerosol (EVA) forcing generator (Toohey et al., 2016). Six 100-member ensembles were created: a control run with zero sulfur emission only using the EVA background aerosol and five volcanic eruption runs $(2.5,5$, 50 10, 20, 40 Tg S) with both the EVA background aerosol and a volcanic eruptions occurring in June 1991 at the Equator, each with 100 ensemble members. Every ensemble member was started from one of the different and independent runs
AOD, waveband $550 \mathrm{~nm}$ [441-625] nm
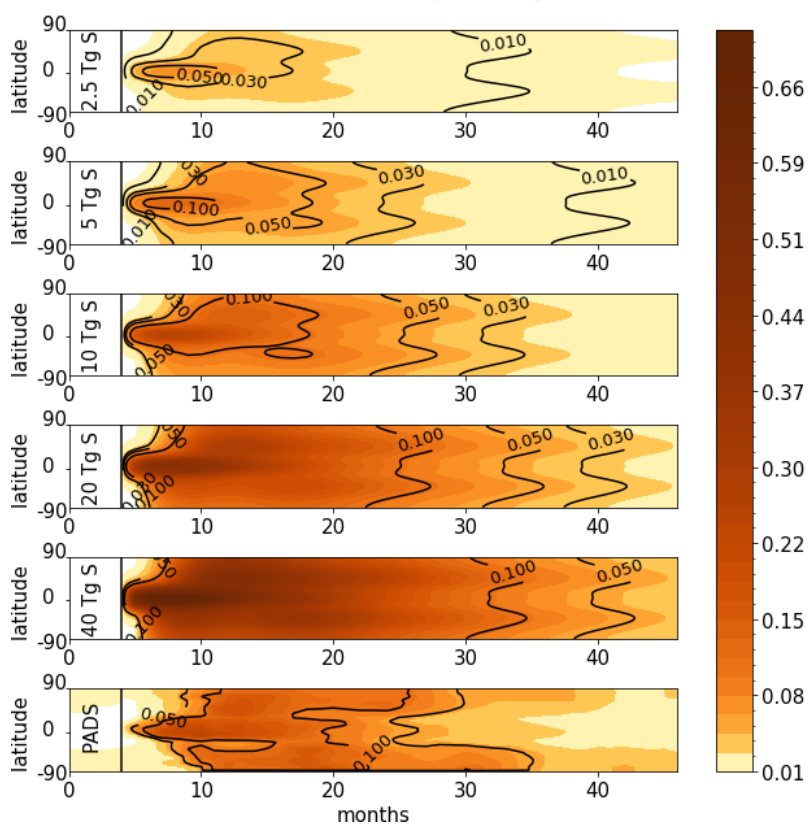

Figure 1. Time evolution of the aerosol optical depth (AOD) for the five volcanically perturbed EVAens runs $(2.5,5,10,20$ and $40 \mathrm{Tg} \mathrm{S})$ and the PADS Mt. Pinatubo compilation. The zonal average AOD is shown for all latitudes considering the $550 \mathrm{~nm}$ waveband (441$625 \mathrm{~nm})$

of the MPI-GE historical simulations in 1991 (Maher et al., 2019). Besides the volcanic aerosols, the forcing files include 55 an aerosol background for the industrialized period supplied by EVA.

The AODs for the five different eruption strengths of the EVA forcing along with the PADS Mt. Pinatubo forcing are shown in Fig. 1 for the $550 \mathrm{~nm}$ waveband. All EVA aerosol distributions have very similar patterns but differ in magnitude and duration of elevated AOD levels. Whereas the $2.5 \mathrm{Tg} \mathrm{S}$ run returns close to background conditions within 3.5 years after the eruption, the $40 \mathrm{Tg} \mathrm{S}$ run only declines to the peak values of the $2.5 \mathrm{Tg} \mathrm{S}$ run within this time. The PADS data set has a higher background AOD level than the EVA data sets in the months before the eruption. With a sulfur amount of $(7.5 \pm 2.5) \mathrm{Tg} \mathrm{S}$ (Timmreck et al., 2018), the Mt. Pinatubo AOD should be comparable to the 5 and 10 Tg S EVA data set (compare Table 1). Generally, the AOD 70 in the PADS data set does not spread as fast to higher latitudes after the eruption. Additionally, the AOD values tend to be slightly higher than the values for the $10 \mathrm{Tg}$ S EVA data set and persist longer at elevated levels.

As we merely prescribe the aerosols, only the indirect vol- 75 canic pathway, which includes cold-point warming and overshooting convection, and not the direct injection or aerosol chemistry is simulated in EVAens. In the following work, all anomalies will be defined as the value difference between 
Table 1. List of tropical volcanic eruptions with location, eruption date and estimated amount of emitted sulfur. The sulfur amounts in parentheses represent the best estimates.

\begin{tabular}{lllrl}
\hline Volcano & Location & Eruption time & Emitted S [Tg] & Reference \\
\hline Mt. Agung & $8^{\circ} \mathrm{S}, 115^{\circ} \mathrm{E}$ & 17 March 1963 & $2.5-5(3.5)$ & Timmreck et al. (2018) and references therein \\
El Chichón & $17^{\circ} \mathrm{N}, 93^{\circ} \mathrm{W}$ & 4 April 1982 & $2.5-5(3.5)$ & Timmreck et al. (2018) and references therein \\
Mt. Pinatubo & $15^{\circ} \mathrm{N}, 120^{\circ} \mathrm{E}$ & 15 June 1991 & $5-10(7)$ & Timmreck et al. (2018) and references therein \\
Tambora & $8^{\circ} \mathrm{S}, 117^{\circ} \mathrm{E}$ & April 1815 & $15-40(30)$ & Marshall et al. (2018) and references therein \\
\hline
\end{tabular}

the volcanically perturbed $(P)$ and unperturbed $0 \mathrm{Tg} \mathrm{S}(U)$ ensemble means $(P-U)$.

\subsection{Stratospherically adjusted clear-sky forcing calculations}

${ }_{5}$ The stratospherically adjusted clear-sky radiative forcing, as defined by Hansen et al. (2005), originating from the increase of stratospheric water vapor due to the indirect volcanic pathway (i.e., via tropopause warming by the aerosol layer), is calculated using the 1-D radiative convective equi10 librium (RCE) model, konrad (Kluft et al., 2019; Dacie et al., 2019). Konrad is designed to represent the tropical atmosphere. It uses the Rapid Radiative Transfer Model for GCMs (RRTMG) and a simple convective adjustment that fixes tropospheric temperatures up to the convective top according to 15 a moist adiabat, whereas the temperatures in the higher atmospheric levels are determined by radiative-dynamical equilibrium. Being a 1-D model, konrad employs a highly parameterized "circulation", i.e., an upwelling term constant in time which only causes adiabatic cooling. As the temperature ${ }_{20}$ above the convective top can adjust, this does not mean that the dynamical heating is fixed (compare Fels et al., 1980).

In order to calculate the stratospherically adjusted SWV forcing, the following procedure is employed: for each eruption strength, including the $0 \mathrm{Tg} \mathrm{S}$ eruption, the ensemble 25 mean of the clear-sky humidity profile in the tropical region $[-5,5]^{\circ}$ latitude is determined from the EVAens output. In order to compute the adjusted radiative forcing due to the increased SWV, the difference between the fluxes in an equilibrated atmosphere with and without the additional SWV so must be calculated. To determine the equilibrated reference without additional SWV, konrad is run to equilibrium with the humidity profile and chemical composition of the atmosphere fixed to the values from the $0 \mathrm{Tg} \mathrm{S}$ runs. The final surface temperature lies between $298-301 \mathrm{~K}$. Starting from this 35 equilibrium state, only the SWV profile is replaced by the volcanically perturbed EVAens humidity profile and a new equilibrium is calculated while keeping the surface temperature fixed but allowing for the temperature above the convective top to adjust. Using both equilibrium states, the ad${ }_{40}$ justed SWV forcing is determined from the flux differences at the top of the atmosphere. The corresponding instantaneous forcing as defined by Hansen et al. (2005) is calculated as the difference of tropopause fluxes obtained without run- ning the perturbed atmosphere into equilibrium. For the allsky case, the contribution of clouds is investigated by additionally taking a $20 \%$ fraction of high-level clouds between 200 and $300 \mathrm{hPa}$ into consideration, while low-level clouds are considered in the albedo settings.

In order to relate the SWV forcing to the aerosol forcing, the instantaneous aerosol forcing is calculated using a dou- ${ }_{50}$ ble radiation call in MPI-ESM. For the double radiation call, fluxes are calculated for each time step once using the atmospheric conditions with and without aerosol. The stratospheric background aerosol is corrected for by additionally calculating the forcing for the corresponding $0 \mathrm{Tg} \mathrm{S}$ run and 55 subtracting it.

\section{Results}

\subsection{Effects on the time evolution of TOA radiative imbalance and surface temperature}

In order to relate the amount of emitted sulfur to its impact on 60 the energy budget of the system, we analyze the TOA radiative imbalance after the volcanic eruptions as well as changes in surface temperature. The time span of negative global radiative TOA imbalance after the volcanic eruptions, during which more energy leaves the Earth-atmosphere system than is taken up, lasts between 17 and 28 months (Fig. 2). For the lower emissions (2.5-5 Tg S), the standard error of the negative TOA imbalance permanently overlaps with zero imbalance. Consequently, single ensemble members of the $0 \mathrm{Tg} \mathrm{S}$ can produce similar signals to these lower emission runs due to internal variability. Overall, the TOA imbalance exhibits a roughly linear relationship with respect to the emitted sulfur mass (see Fig. A1). As a consequence of the negative TOA imbalance, the surface temperatures in the volcanically perturbed runs decrease. The range of ensemble mean max- 75 imum global temperature decrease for EVAens is -0.09$1.30 \mathrm{~K}$ (Fig. 2). As the surface temperature follows the TOA imbalance, the change in surface temperature is also roughly linear with respect to the emitted S mass (Fig. A2).

In addition to the EVAens results, the TOA imbalance 80 and global surface temperature changes for the historical Mt. Pinatubo eruption are shown in black in Fig. 2. The global TOA imbalance, peaking at $-2.4 \mathrm{~W} \mathrm{~m}^{-2}$, compares favorably with the approximately $-3 \mathrm{~W} \mathrm{~m}^{-2}$ from Earth Ra- 

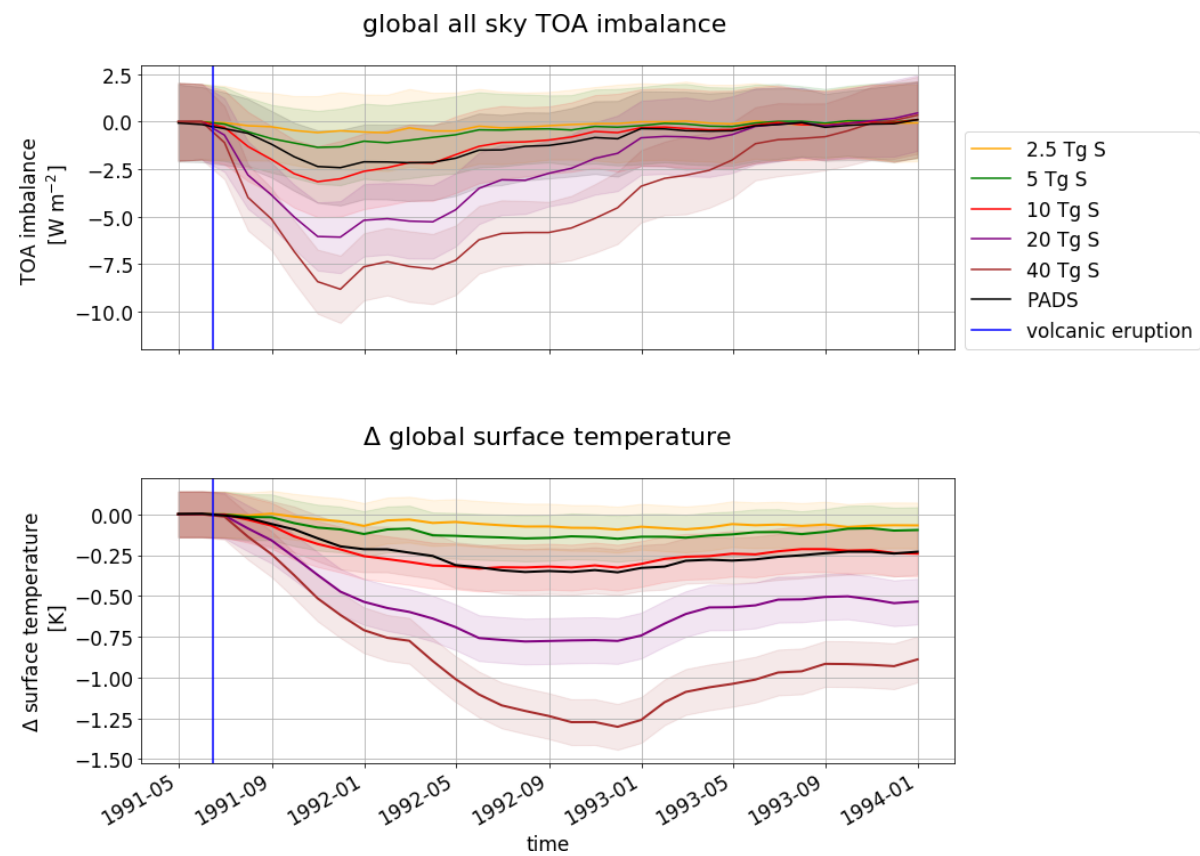

Figure 2. Global top-of-atmosphere (TOA) radiative imbalance and anomaly of surface temperature in the five volcanically perturbed EVAens runs $(2.5,5,10,20$ and $40 \mathrm{Tg} \mathrm{S})$. For each run, the standard errors of the mean are denoted by shading. The vertical blue line marks the eruption time. The plots also show the values for the MPI-GE historical simulations (PADS).

diation Budget Satellite observations (Soden et al., 2002) when considering the standard deviations of our ensemble. The average surface cooling between June 1991 and December 1993 is $-0.26 \mathrm{~K}$, with a maximum cooling of $-0.36 \mathrm{~K}$ in 5 our simulations, whereas the cooling documented by satellite measurements from the microwave sounding unit (MSU) was $-0.3 \mathrm{~K}$ between June 1991 and December 1995 after El Niño-Southern Oscillation (ENSO) removal and reached a peak cooling of $-0.5 \mathrm{~K}$ (Soden et al., 2002).

\section{${ }_{10} 3.2$ Effects on the cold-point temperature}

In the following analysis, the cold point is estimated as the lowest temperature in the tropical tropopause layer (TTL) region lying on full pressure levels of model output remapped to a vertical spacing of $10 \mathrm{hPa}$ in the tropical tropopause re15 gion. The associated errors in average cold-point temperature lie below $\pm 1.1 \mathrm{~K}$. The effect of the volcanic forcing on the inner tropical temperature profile is visualized in Fig. 3 showing the EVAens ensemble mean of the temperature profiles 3 months after the eruption. The month of September was ${ }_{20}$ chosen as an example since it lies in the season of relatively large water vapor entry into the stratosphere due to a maximum cold-point temperature in boreal autumn and winter. Due to the location of the aerosol peak above the cold point, the largest temperature changes occur in the lower strato${ }_{25}$ sphere, with increases up to $24 \mathrm{~K}$ in the $40 \mathrm{Tg} \mathrm{S}$ ensemble. The cold-point warming reaches maximum values of $8 \mathrm{~K}$ in the case of the $40 \mathrm{Tg} \mathrm{S}$ run. Also visible in the figure is the downwards shift of the cold point with increasing sulfur burden caused by the stratospheric warming. This effect is amplified by tropospheric cooling (compare surface cooling in Fig. 2) due to the backscattering of solar radiation through the volcanic aerosols.

Figure 4 shows the temporal evolution of the surface temperature (a), cold-point temperature (b) and $70 \mathrm{hPa}$ specific humidity (c) as the difference to the zero emission run in the inner tropics. Whereas the surface temperature decreases due to the scattering of incoming shortwave radiation by the volcanic aerosols, the cold-point temperature increases due to warming of the tropopause layer by absorption of terrestrial longwave and solar near-IR radiation by the aerosol layer.

When considering the ensemble mean and its standard error, even the temperature changes of the low emission runs (2.5 and $5 \mathrm{Tg} \mathrm{S}$ ) are significantly different from the control run for short periods of time. With a maximum value of $0.99 \mathrm{~K}$, the ensemble mean for the cold-point temperature of the $5 \mathrm{Tg} \mathrm{S}$ is the lowest sulfur emission to reach a mean warming above the control run standard deviations, which are 10 times larger than the standard error for our 100 -member ensemble and reach maximum values of $0.73 \mathrm{~K}$. Cold-point values below the standard deviation range could 50 be found for single-control-run ensemble members due to internal variability. The higher emission scenarios (20 and $40 \mathrm{Tg} \mathrm{S}$ ) have longer periods with cold-point temperature changes above the normally observed internal variability. In addition, the $40 \mathrm{Tg} \mathrm{S}$ emission group shows a second amplifi- 55 


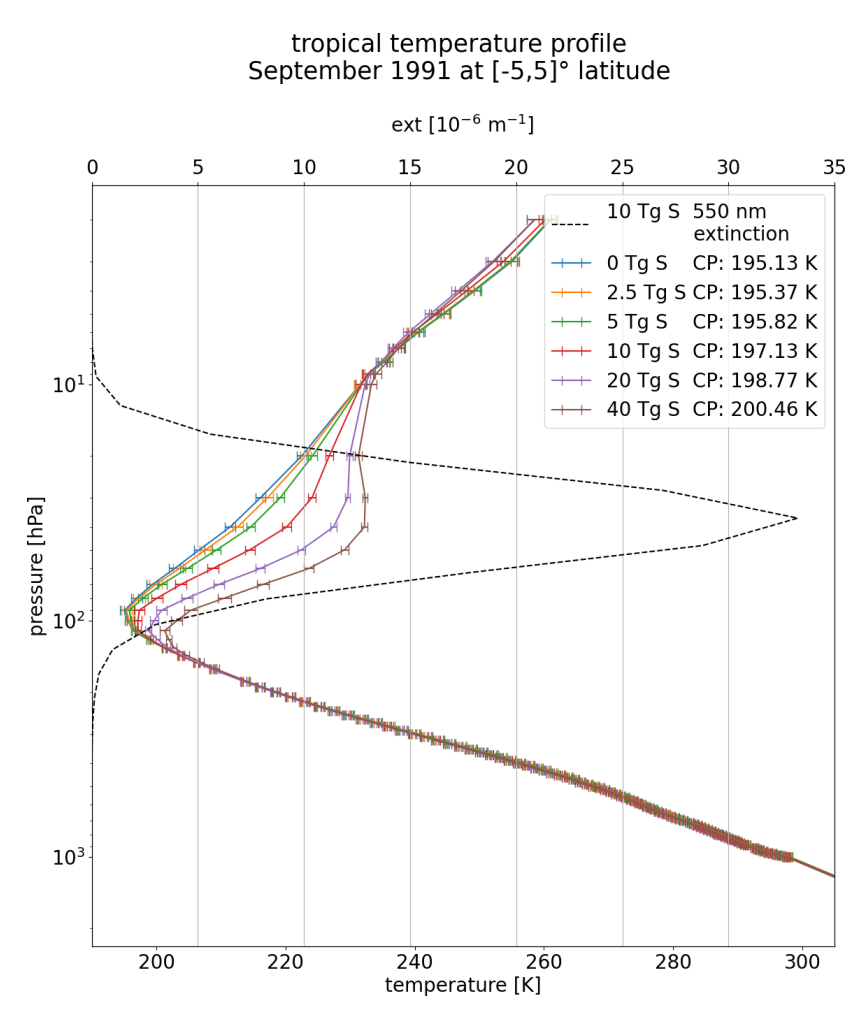

Figure 3. Inner tropical average of the temperature profiles for the five volcanically perturbed EVAens runs $(2.5,5,10,20$ and $40 \mathrm{Tg} \mathrm{S})$ in September 1991 (3 months after the eruption). The temperature of the respective cold point $(\mathrm{CP})$ is indicated in the legend. The solid line represents the ensemble mean; the error bars symbolize the ensemble standard deviations. The $550 \mathrm{~nm}$ extinction values for the $10 \mathrm{Tg} \mathrm{S}$ aerosol profile are shown with a dashed black line.

cation peak of the yearly cycle of the cold-point temperatures between May and September 1992.

The monthly changes in cold-point temperature are not linear, neither with respect to emitted sulfur mass nor to AOD 5 in the prominent IR waveband (compare Figs. A3, A4). Additionally, the transient behavior of the volcanic forcing - the buildup phase in 1991, the approximately constant forcing in 1992 and the declining phase in 1993, which also differ between the individual eruption sizes - leads to a hysteretic be10 havior. Nevertheless, when partitioning the cold-point warmings into these individual phases, the dependence of the coldpoint warming on IR AOD can be described with a power function of form $a \mathrm{AOD}^{b}+c$ for the years 1991, 1992 and 1993 (Fig. 5).

15 The found cold-point temperature increases are accompanied by an increase in the saturation water vapor pressure, reducing the "freeze trap" drying in the cold-point region. The increased saturation water vapor pressure enables more water vapor to enter the lower stratosphere as shown in Fig. 4c.

${ }_{20}$ Consequently, the evolution of the additional stratospheric water vapor closely follows the evolution of the cold-point temperature changes.

\subsection{Effects on the tape recorder signal}

The manifestation of the annual cycle of the tropical SWV as seen in the vertical profile is often described as the tape 25 recorder signal (Mote et al., 1996): the variations of the tropical cold-point temperatures controlling the water vapor entry into the stratosphere via the saturation water vapor pressure are imprinted on the stratospheric water vapor as music is imprinted on a tape. This leads to an annual cycle of 30 bands of high and low water vapor content propagating upwards in the stratosphere with the BDC. As the heating by the volcanic aerosols will lead to increased tropical cold-point temperatures, an increase of stratospheric water vapor is expected after volcanic eruptions with stratospheric aerosols. As shown in Sect. 3.2, the specific humidity shows an enhancement which does not stay constant and then declines but has an annual cycle like the tape recorder. In the following section, we will investigate the seasonal cycle more closely. Figures 6 and 7 show absolute SWV and the differences in the SWV content above $140 \mathrm{hPa}$ with respect to the control run for all five eruption strengths. The maximum increases are found in the eruption year itself ranging from $0.1 \mathrm{ppmv}$ for the $2.5 \mathrm{Tg} \mathrm{S}$ eruption to more than $5 \mathrm{ppmv}$ for the $40 \mathrm{Tg} \mathrm{S}$ eruption. This corresponds to $5 \%$ in 45 the case of the $2.5 \mathrm{Tg} \mathrm{S}$ simulation and $160 \%$ in the case of the $40 \mathrm{Tg}$ S simulation (see Fig. B1). The larger the eruption, the earlier the increase becomes visible and is significant. The additional SWV also follows the annual cycle of the tape recorder (Mote et al., 1996), showing maxima in the SWV enhancement around September which then propagate upwards. This seasonal variation is also apparent in the behavior of the tropopause and cold-point heights: for scenarios with at least $10 \mathrm{Tg} \mathrm{S}$ onward the tropopause pressures and cold-point pressures are higher in the Northern Hemisphere autumn, whereas in the 20 and $40 \mathrm{Tg} \mathrm{S}$ runs the volcanic forcing leads to higher pressure levels of the cold point from September 1991 until the end of 1992 accompanied by a seasonal signal in the SWV anomalies. Allowing for more water vapor to transit to the lower stratosphere. In the $40 \mathrm{Tg} \mathrm{S}$ ensemble mean, the second seasonal cycle is associated with an upward propagation of the SWV increases above 4 ppmv to even lower atmospheric pressures than in the preceding year. This behavior can be attributed to the persistence of the high levels of aerosols in combination with the already-enhanced 6 SWV levels due to the presence of the aerosol in the previous year, the additional warming caused by the SWV and the lower-lying cold point. Shortly after the eruption, a decrease in water vapor content above $50 \mathrm{hPa}$ is visible. At these altitudes, SWV increases with height due to its production 70 by methane oxidation, which is parameterized in MPI-ESM (Schmidt et al., 2013). Heating in the aerosol layer below leads to lofting of air parcels, bringing lower humidity air upwards to higher altitudes, where it causes a net reduction in humidity. However, this effect never exceeds $0.8 \mathrm{ppmv}$ and 75 


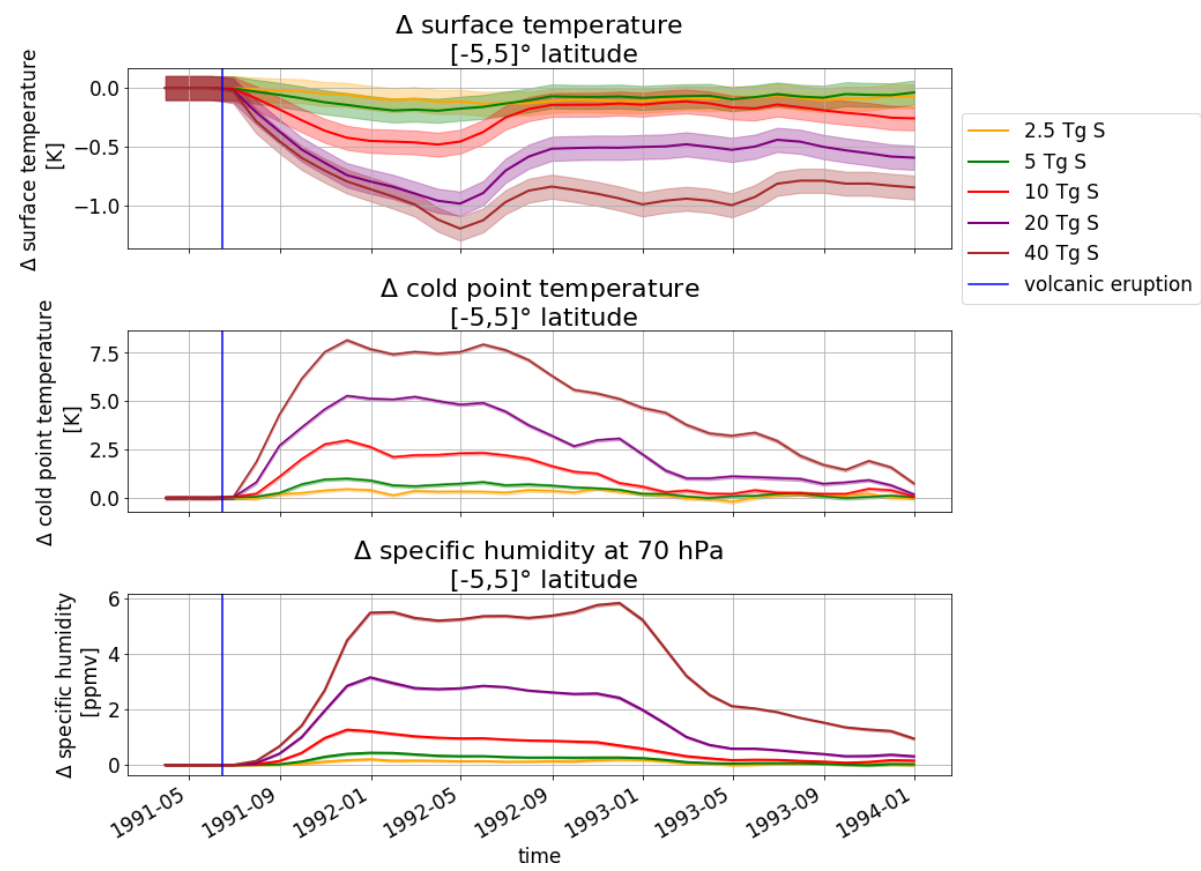

Figure 4. Temporal evolution of the inner tropical mean anomaly in surface temperature, cold-point temperature and stratospheric water vapor between volcanically perturbed and unperturbed ensemble runs. The ensemble means are shown with their standard errors. The time of the volcanic eruption is indicated by a vertical blue line.
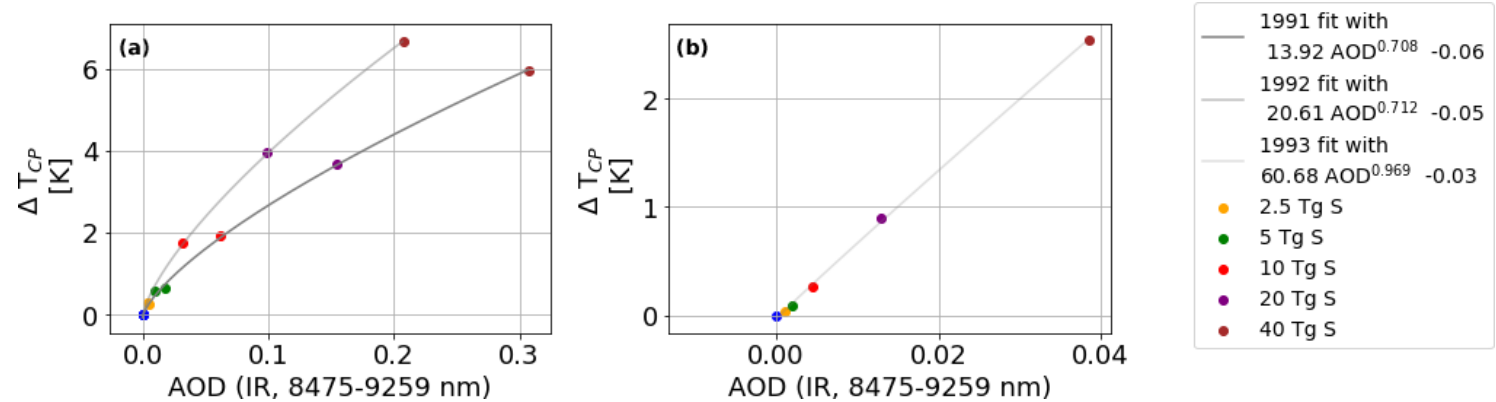

Figure 5. Yearly averages of adjusted tropical cold-point temperature increases as a function of tropical AOD (IR, 8475-9259 nm) for the 3 examined years (1991-1993). A power function fit of form $a \mathrm{AOD}^{b}+c$ for each year with a corresponding equation is shown.

is offset as soon as the lifted air becomes more moist due to enhanced SWV entry through the tropopause region.

\subsection{Intra-ensemble variability}

The investigation of single ensemble members is of interest 5 because - unlike for the ensemble mean - their physical characteristics would actually be "observable". Figure 8 shows seasonal averages of the specific humidity at the cold point as a function of cold-point temperature for the inner tropical average in 1991 and 1992. The season of September-October-

10 November (SON) was chosen, as it follows the period where the entry value of stratospheric water vapor is highest, leading to the highest SWV in the tropical lower stratosphere. Each point in Fig. 8 symbolizes a single ensemble member.
Orange crosses show the theoretically possible maximum specific humidity curve calculated as the saturation humidity for water vapor over ice at the average cold-point temperature, using the corresponding exact solution for the ClausiusClapeyron equation by Murphy and Koop (2005) ${ }^{1}$. An approximation for the Clausius-Clapeyron equation at this temperature range with a $12 \%$ increase of specific humidity per Kelvin is indicated by a dashed gray line. This approximation is based on the assumption that the atmosphere around the cold point is saturated in the $0 \mathrm{Tg} \mathrm{S}$ run. The single ensemble

\footnotetext{
${ }^{1}$ Formula (7) giving the saturation water vapor pressure above ice $p_{\text {ice }}$ as $p_{\text {ice }}=\exp (9.550426-5723.265 / T+3.53068 \ln (T)-$ $0.00728332 T)$ is used. This formula is valid for temperatures above $110 \mathrm{~K}$. With the knowledge of $p_{\text {ice }}$ and the respective total pressure, a calculation of the specific humidity is possible.
} 


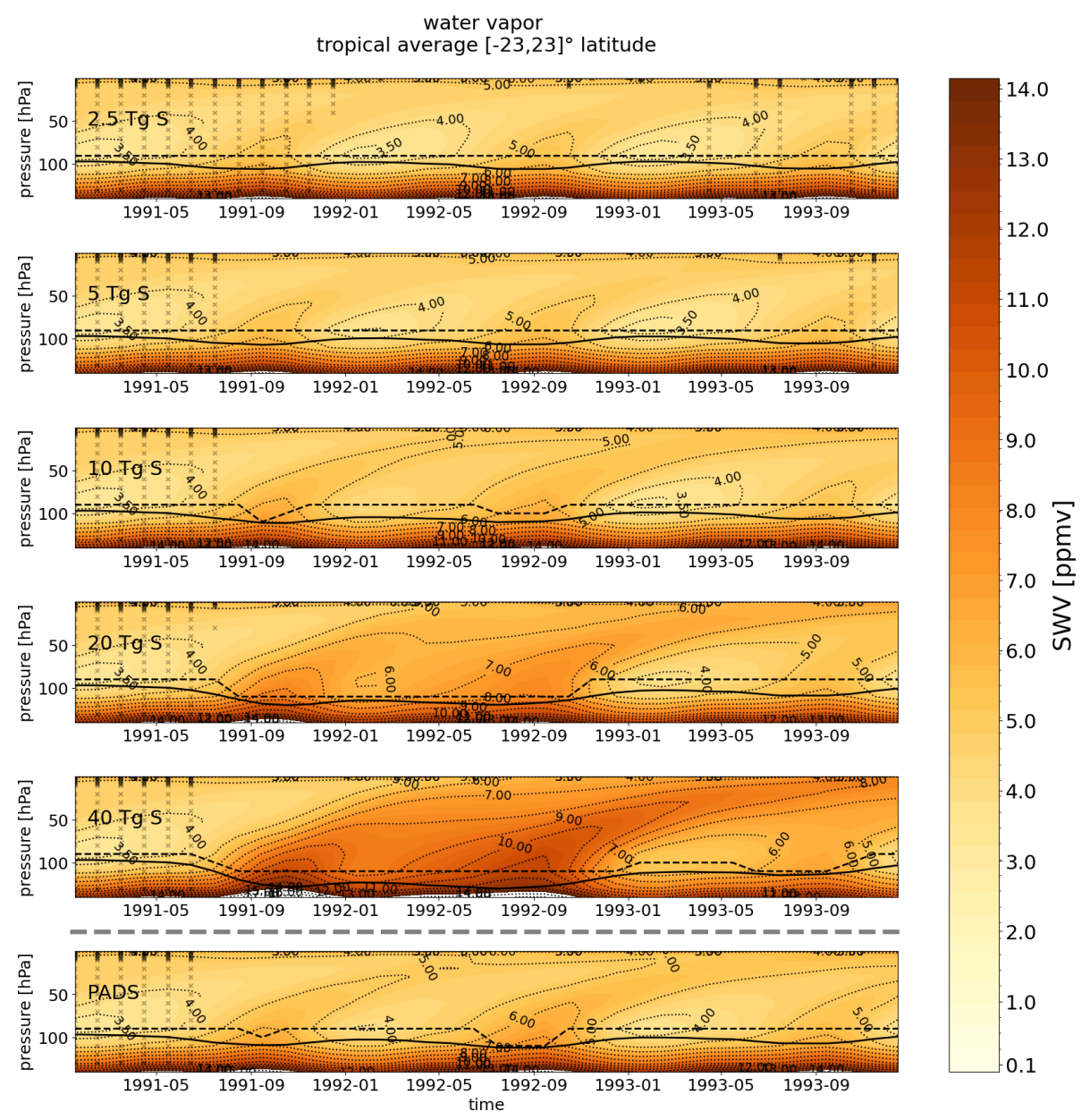

Figure 6. Tropical average in $[-23,23]^{\circ}$ latitude of $\mathrm{WV}$ above $140 \mathrm{hPa}$ for sulfur injections of $2.5,5,10,20$ and $40 \mathrm{Tg} \mathrm{S}$ as well as the PADS data set. The World Meteorological Organization (WMO)-tropopause pressure is indicated by a black line and the cold-point pressure is denoted by the dashed black line. Absolute values are shown. In regions not covered by black crosses, statistically significant differences between water vapor values of the perturbed and unperturbed runs $(t$ test at $p=0.05)$ were found.

members follow the slopes and values of the calculated water vapor amount at saturation in the inner tropics $\left([-5,5]^{\circ}\right.$ latitude). In addition to water vapor, sublimated lofted ice can also contribute to the SWV, leading to higher values than ex5 pected based on the saturation water vapor alone. Overshooting events are considered in our convective parameterization (Möbis and Stevens, 2012). However, at the location of the cold point, this lofted ice would still be in the ice state and not accounted for in the specific humidity term. In the inner 10 tropics, the simulated specific humidity values agree nicely with those from the Clausius-Clapeyron equation and its approximated WV dependence on a $12 \%$ increase of SWV per Kelvin. Considering the simplification of taking the average cold-point temperatures between $[-5,5]^{\circ}$ latitude instead of 15 the minimum cold-point temperatures, this agreement is surprisingly good. Oman et al. (2008), for example, only found good agreement when considering the minimum cold-point temperatures in the tropics. As they were analyzing a band between $[-10,10]^{\circ}$ latitude, a factor contributing to the difference to our result could be that the main contribution to dehydration of air parcels during their horizontal motion in the vertical ascent takes place in the inner tropics (Schoeberl and Dessler, 2011), the region to which our study is restricted. Consistent with this analysis is the stronger discrepancy of approximately $1.6 \mathrm{ppmv}$ between the SWV values predicted using the Clausius-Clapeyron equation and the SWV output by the model when averaging over the entire tropics (compare Fig. C1).

In the first SON after the eruption in 1991, the SWV values and cold-point temperatures are larger than those in 1992. зо Additionally, the separation by sulfur content is more pronounced in 1991. Table 2 lists the number of individual ensemble members lying within 2 standard deviations of the temperature or humidity value spread of the control run. In 1991, several individual group members up to the $5 \mathrm{Tg} \mathrm{S}$ run ${ }_{35}$ overlap with the control run spread as far as changes in cold- 
differences in water vapor

tropical average $[-23,23]^{\circ}$ latitude

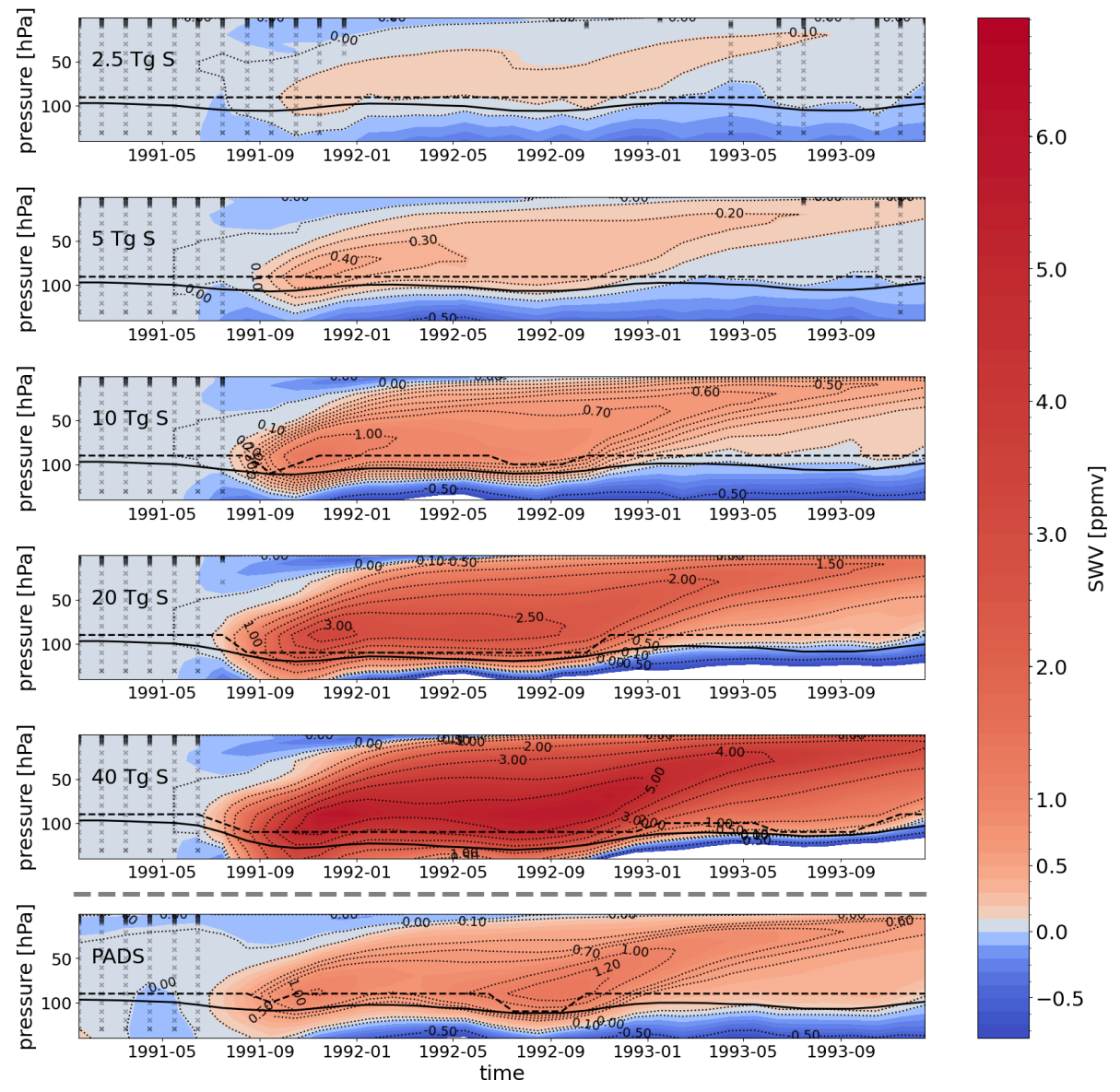

Figure 7. Tropical average in $[-23,23]^{\circ}$ latitude of $\mathrm{WV}$ anomalies above $140 \mathrm{hPa}$ for the sulfur injections of $2.5,5,10,20$ and $40 \mathrm{Tg} \mathrm{S}$ as well as the PADS data set. The lowermost panel shows the MPI-GE historical simulations for Mt. Pinatubo using the PADS forcing data set discussed in Sect. 3.5. The WMO-tropopause pressure is indicated by a black line and the cold-point pressure is indicated by a dashed black line. Differences with respect to the $0 \mathrm{Tg} \mathrm{S}$ control run are shown. In regions not covered by black crosses, statistically significant differences between water vapor values of the perturbed and unperturbed runs ( $t$ test at $p=0.05$ ) were found.
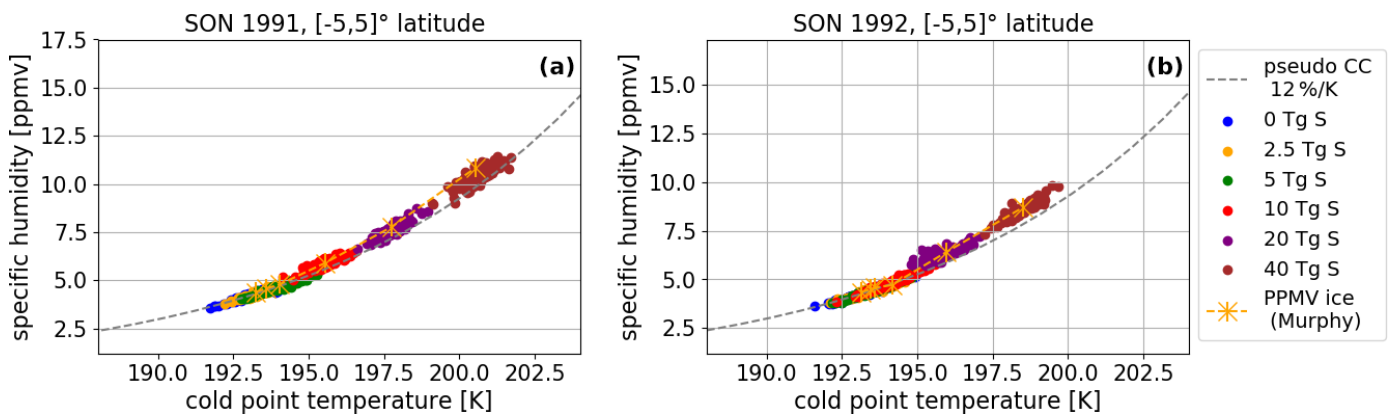

Figure 8. Seasonal averages of specific humidity at the cold point as a function of cold-point temperature for SON 1991 (a) and 1992 (b). Values for each individual ensemble member are shown as dots for the inner tropics. An approximation (see text) for the Clausius-Clapeyron equation at this temperature range with an $12 \%$ increase of specific humidity per Kelvin is indicated by a dashed gray line. The exact solution for the Clausius-Clapeyron equation over ice by Murphy and Koop (2005) is calculated for the average ensemble cold-point temperatures and pressure and shown in orange. 
Table 2. Number of ensemble members lying within the 2 standard deviations of the corresponding control run values with respect to temperature $(T)$ or specific humidity $(Q)$ or their union $(Q \cup T)$ in 1991 and 1992.

\begin{tabular}{lrrrrr}
\hline Case & $2.5 \mathrm{Tg} \mathrm{S}$ & $5 \mathrm{Tg} \mathrm{S}$ & $10 \mathrm{Tg} \mathrm{S}$ & $20 \mathrm{Tg} \mathrm{S}$ & $40 \mathrm{Tg} \mathrm{S}$ \\
\hline$Q_{1991}$ & 93 & 76 & 0 & 0 & 0 \\
$T_{1991}$ & 92 & 79 & 1 & 0 & 0 \\
$(Q \cup T)_{1991}$ & 93 & 82 & 1 & 0 & 0 \\
$Q_{1992}$ & 97 & 89 & 52 & 0 & 0 \\
$T_{1992}$ & 98 & 90 & 65 & 0 & 0 \\
$(Q \cup T)_{1992}$ & 99 & 90 & 65 & 0 & 0 \\
\hline
\end{tabular}

point temperature and humidity values are concerned. The $10 \mathrm{Tg} \mathrm{S}$ run marks the emission strength at which single ensemble members start to be significantly different from the control run as only one ensemble member cannot be distin${ }_{5}$ guished from the control run using only the temperature values. The $20 \mathrm{Tg} \mathrm{S}$ run is the first emission strength with no control run overlap and for which all individual ensemble members show a significant increase of SWV content and cold-point temperatures in 1991 and even in 1992 where the

10 lower emission runs start to show an increasing number of ensemble members overlapping with the control run values again. This analysis shows the difficulty to register the SWV increases in observational data which collect data for a single realizations of a volcanic eruption. Although signals similar 15 to those of individual eruptions can be produced by internal variability of an unperturbed scenario, our larger ensemble size allows us to extract a robust signal which may be obscured in a single observational record.

\subsection{Comparison to the MPI-GE historical simulations (Mt. Pinatubo)} 20

The importance of the aerosol profile shape and particularly the extinction at the cold point for the SWV entry becomes apparent when comparing the results of the EVAens members to the Mt. Pinatubo period in the MPI-GE historical ${ }_{25}$ simulations. In terms of the amount of emitted sulfur, the EVAens simulations for 5 and $10 \mathrm{Tg} \mathrm{S}$ can be seen as bounds of recent estimates of the sulfur emission of the Mt. Pinatubo eruption of (7.5 \pm 2.5$) \mathrm{Tg} \mathrm{S}$ (Timmreck et al., 2018). As the PADS data set describing the Mt. Pinatubo eruption is based 30 on observational evidence rather than simulation results, as is the case for the EVA data sets, only a range and not a set amount of emitted sulfur is given. In Fig. 2, which shows the global mean TOA radiative imbalance for the MPI-GE historical simulations along with the EVAens simulations, the ${ }_{35}$ values for the Mt. Pinatubo eruption in the MPI-GE historical simulations lie between the 5 and the $10 \mathrm{Tg} \mathrm{S}$ imbalances in 1991. In 1992, the mean MPI-GE TOA imbalance is slightly more negative than the ensemble mean of the $10 \mathrm{Tg} \mathrm{S}$ run, but overall the deviations between the $10 \mathrm{Tg} \mathrm{S}$ run and Mt.

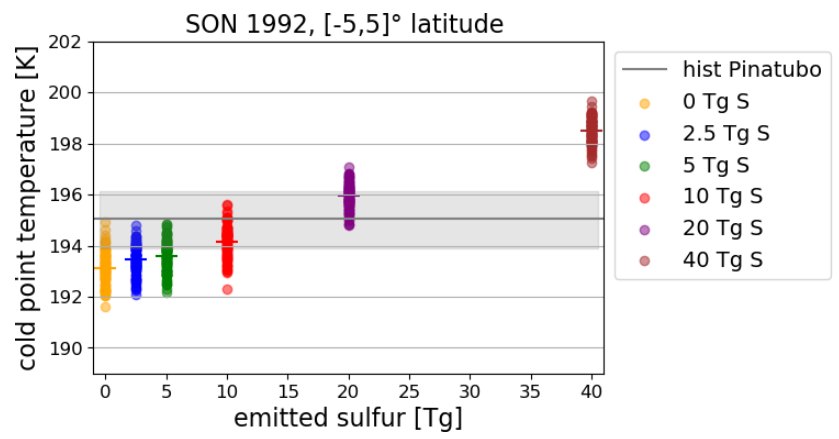

Figure 9. Average cold-point temperature in the inner tropical region $[-5,5]^{\circ}$ latitude as a function of emitted sulfur for all EVAens members in SON 1992. Each point symbolizes one ensemble member; the horizontal lines denote the ensemble mean. The average cold-point temperature range for the historical Mt. Pinatubo eruptions (PADS) is shown as a gray line; the shaded region shows the extent between corresponding maximum and minimum cold-point temperature.

Pinatubo run in the MPI-GE historical simulations are small 40 compared to the standard error of the ensemble means.

However, the tropical 1992 SWV anomalies in the historical simulations show a stronger increase than in the $10 \mathrm{Tg} \mathrm{S}$ EVAens simulations (absolute values are shown in Fig. 7; for percental changes, see Fig. B1). In particular, the SWV 45 increases show a seasonality enhancing the tape recorder amplitude in the historical simulations which is not present to that extent in the EVAens simulations. Notable is also a stronger SWV increase of $1.2 \mathrm{ppmv}$ in the Mt. Pinatubo simulations of 1992 exceeding the $1.0 \mathrm{ppmv}$ of 1991 . The heights the corresponding SWV increases reach also differ: the $0.7 \mathrm{ppmv}$ signal propagates upwards to $20 \mathrm{hPa}$ in the historical run, whereas in the $10 \mathrm{Tg} \mathrm{S}$ run the $0.7 \mathrm{ppmv}$ signal only reaches pressure levels of up to $50 \mathrm{hPa}$.

The higher SWV values are caused by a stronger heating 55 of the atmospheric region around the cold point, controlling the indirect volcanic SWV entry. Figure 9 shows cold-point temperatures for the example of SON 1992. Mt. Pinatubo in the MPI-GE historical simulations reaches values lying between those of the 10 and $20 \mathrm{Tg} \mathrm{S}$ run. This can be understood when comparing the aerosol extinction profiles of EVA and PADS as a proxy for the heating generated by the aerosol layer (Fig. 10).

Although the PADS data set Mt. Pinatubo forcing has a peak value lying between the 5 and $10 \mathrm{Tg}$ S EVA extinc- 65 tions, the extinction at the tropopause and cold-point pressure is slightly higher than the $10 \mathrm{Tg}$ S extinction in September 1991 (Fig. 10a and c). In September 1992, the PADS data set reaches values of the $20 \mathrm{Tg}$ S EVA in the cold-point region and a peak extinction comparable to the $10 \mathrm{Tg}$ S profile 70 (Fig. 10b and d). A similar behavior is apparent in the solar extinction bands (see Appendix Fig. D1). As the warming of the cold point determines the SWV entry anomaly, the ex- 
aerosol extinction (IR, 8475-9259 $\mathrm{nm}$ )
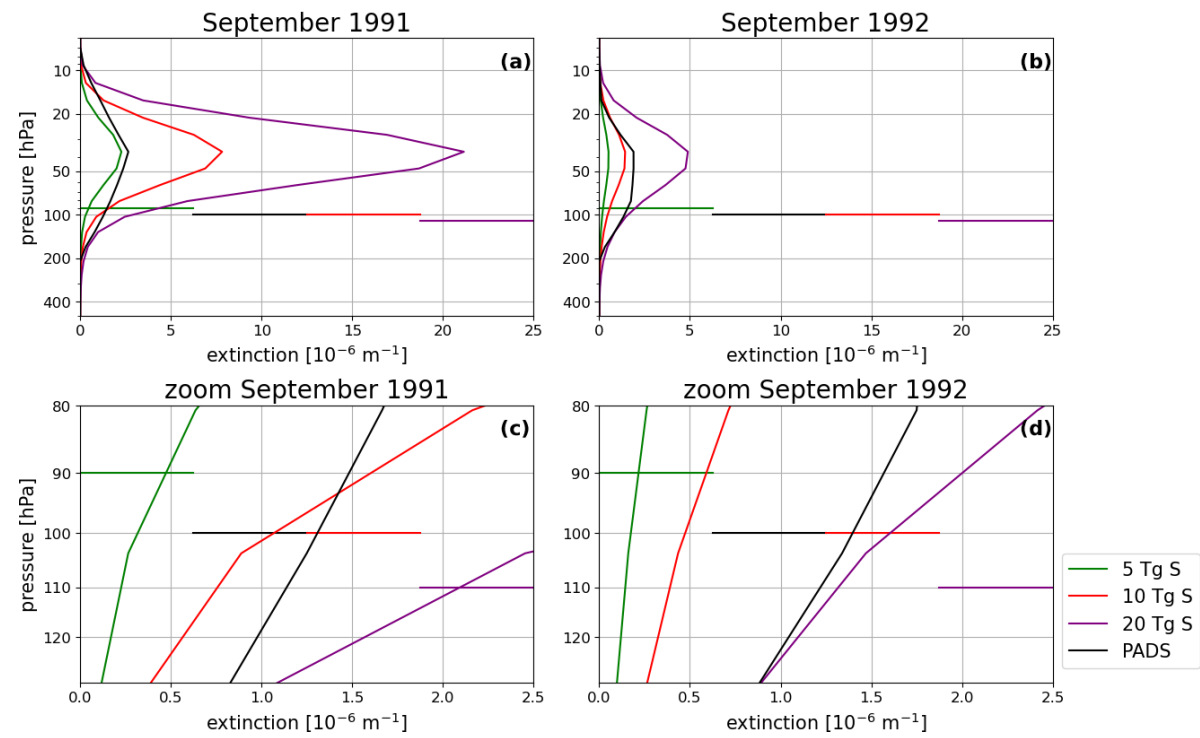

Figure 10. Average tropical aerosol extinction in the $8475-9259 \mathrm{~nm}$ infrared waveband from EVA for 5, 10 and $20 \mathrm{Tg}$ S emissions as well as from PADS in September 1991 and 1992. The horizontal lines indicate the pressure levels of the cold point in the region between [-5, 5 $]^{\circ}$ latitude for each eruption strength. Panels (a) and (b) show the entire profile. Panels (c) and (d) are zooms of the cold-point region.

tinction values at this point will have a significant impact. In 1991, the $10 \mathrm{Tg}$ S EVA extinction values at the cold point are only slightly weaker than the extinction values of the PADS forcing set. The SWV values in the MPI-GE historical simu5 lations are closer, but not equal, to those in the $10 \mathrm{Tg} \mathrm{S}$ as the peak extinction values in the $10 \mathrm{Tg} \mathrm{S}$ are more than 2 times larger than the PADS extinction values and partially compensate the lower values at the cold point. In 1992, the situation changes, and MPI-GE shows higher SWV values than the 10 $10 \mathrm{Tg}$ S ensemble. The amplification of the SWV entry in the second SON season after the eruption can be attributed to three phenomena. First, the heating was only building up in the Northern Hemisphere summer of 1991 and had not yet reached its maximum value, as can be seen in the plot for the 15 cold-point temperatures (Fig. 4). Second, the peak extinction values of the PADS data set start to exceed the $10 \mathrm{Tg}$ S values in 1992, which may lead to higher SWV entry values (Fig. 11a). Third, the LW extinction at the cold point reaches a second, larger maximum around the northern summer of 20 1992 with values comparable to $20 \mathrm{Tg}$ S. This second maximum is not represented in the EVA forcing (Fig. 11b) and goes along with a decrease in the peak forcing difference in EVAens, which led to higher SWV entry values in EVAens in 1991. The larger difference between peak extinction and 25 extinction at the cold point compensated for the very similar extinction values at the cold point in 1991.

\subsection{Adjusted forcing caused by the SWV increases}

In the following, the adjusted SWV forcing is investigated using the one-dimensional model konrad, as described in
Sect. 2.2. Figure 12a shows flux anomalies between an unperturbed run and a run perturbed with the increased SWV levels of the $40 \mathrm{Tg} \mathrm{S}$ run but without the volcanic aerosols. Although SWV levels are increased within the complete stratospheric column, the main flux changes occur in the tropopause region where the enhancement is largest, the atmosphere denser and the effect of stratospheric water vapor on the radiative forcing strongest (Solomon et al., 2010). In this region, the incoming solar radiation ( $\mathrm{SWd}$ ) is reduced by absorption, while at lower altitudes there is no difference in the shortwave flux. This is caused by the SWV absorbing part of the solar spectrum which, amongst others, tropospheric water vapor completely absorbs at lower altitudes in the unperturbed run. The reflected solar radiation $(\mathrm{SWu})$ at the surface is only changed negligibly since $\Delta \mathrm{SWd}$ at the surface is also negligible.

Consequently, the SW contribution ( $\mathrm{SWd}-\mathrm{SWu}$ ) to the adjusted forcing at the TOA is very small and negative - accounting for a slightly increased scattering due to the SWV. The emitted longwave radiation ( $\mathrm{LWu}$ ) near the surface is unchanged. This is due to our setup: as the surface temperature is fixed in the perturbed run, the surface LWu is fixed as well. The SWV leads to an increase in the tropopause temperatures, following this increase the emitted longwave radiation at the main SWV levels is also increased, as can be seen in the increased downward longwave radiation (LWd). The $\mathrm{LWu}$ above the tropopause region is substantially reduced as the SWV acts as a greenhouse gas and traps part of the outgoing radiation. This leads to the characteristic net positive forcing of the greenhouse gas at the TOA. A comparison 

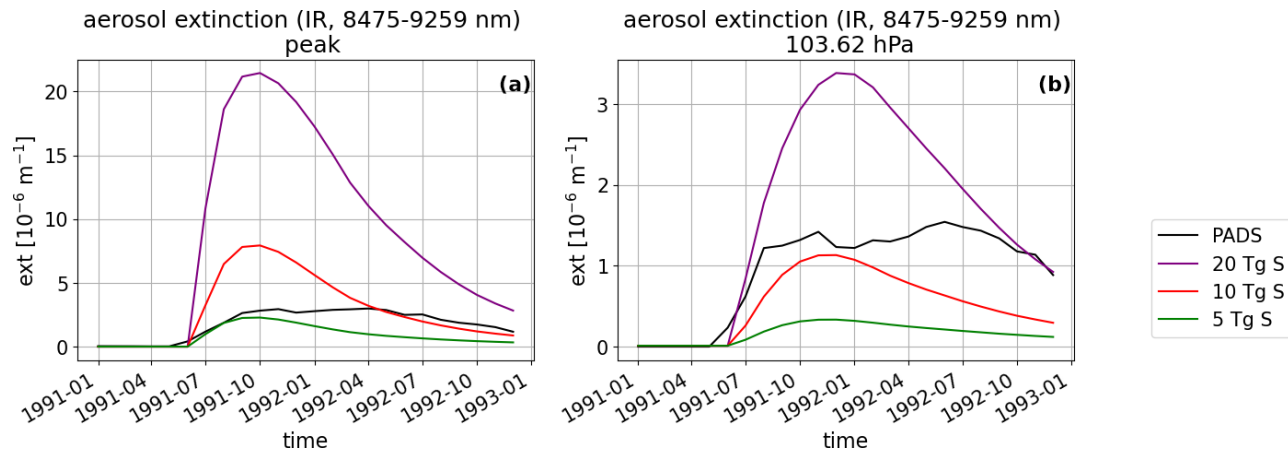

Figure 11. Temporal evolution of the aerosol extinction at the profile peak (a) and the cold-point region (b) for the 8475-9259 nm IR waveband.

to the instantaneous forcing (Fig. 12b) shows that the temperature adaptations in the stratosphere significantly amplify the SWV forcing at the TOA. Whereas the atmospheric levels with increased SWV are warmed, stratospheric cooling is ${ }_{5}$ found in higher atmospheric levels, reducing the $\mathrm{LWu}$. This effect has to build up though and consequently is more pronounced in the adjusted SWV forcing. If, in addition to the stratosphere, the troposphere was also allowed to adjust, part of this effect may be counterbalanced (Huang et al., 2020).

10 The temporal evolution of the adjusted inner tropical SWV forcing is shown for all five eruption strengths in Fig. 13. The adjusted forcing caused by the SWV, corresponding to the 2.5 to $10 \mathrm{Tg} \mathrm{S}$ run, is below the maximum fluctuations caused by internal variability denoted by the gray line in Fig. 13. The 15 forcing found for these runs could be found for one ensemble member in the $0 \mathrm{Tg}$ case as well, although the time span in which it would occur would most probably be shorter. The adjusted SWV forcing for the $40 \mathrm{Tg} \mathrm{S}$ run reaches values of up to $0.65 \mathrm{~W} \mathrm{~m}^{-2}$. The signal evolution, especially in the 20 20 and $40 \mathrm{Tg} \mathrm{S}$ cases, matches the evolution already observed for the SWV increases in the tropical region, with two seasonal peaks. However, since SWV at pressures lower than $100 \mathrm{hPa}$ also contributes to the total forcing - although to a smaller extent - and the transport out of the tropical re${ }_{25}$ gion with the BDC is slow, the first peak forcing times are longer than the peak specific humidity values at $100 \mathrm{hPa}$ in Fig. 4. When considering clouds, the stratospherically adjusted forcing caused by the additional SWV is slightly increased, by $0.1 \mathrm{~W} \mathrm{~m}^{-2}$ at most (compare Appendix Fig. E2). ${ }_{30}$ As the clouds reflect part of the downgoing SW radiation, some of the SW bands, which could be completely absorbed while traveling through the complete stratosphere and troposphere, are not absorbed entirely. The additional SWV in the stratosphere increases the absorption in these bands and re${ }_{35}$ duces the outgoing SW radiation. This leads to an increase of the forcing.

The monthly SWV forcing does not exhibit a linear behavior with respect to the mass of emitted sulfur or main IR AOD waveband (Figs. A5, A6), as was expected since the monthly cold-point temperatures also did not change in a linear manner with respect to the emitted sulfur mass and the temperature increases showed a hysteretic behavior. However, again, when averaging out the seasonal dependencies and partitioning the time after the eruption in the signal buildup phase (1991, after the eruption), the phase of approximately constant forcing (1992) and the phase of declining signal (1993), the relationship can be fitted to a power function of form $a \mathrm{AOD}^{b}+c$ in the region of interest (Fig. 14). Compared to the cold-point-AOD relation, the signal buildup and relaxation back to the ground state are damped as the transport 50 of the SWV into the stratosphere and out of the tropical region takes place over longer timescales than the cold-point warming or cooling, respectively.

As the SWV forcing counteracts the volcanic forcing, its relation to the aerosol forcing is of interest. Figure 15a shows 55 the tropical aerosol forcing as calculated using the double radiation call in MPI-ESM. For the evaluation of the forcing in the double radiation call, different conventions exist as far as the evaluations at the TOA or the tropopause are concerned (e.g., compare Forster et al., 2016). As the double radiation 6 call is used to determine an instantaneous forcing, the readout at the tropopause level would be following the standard convention as defined by Hansen et al. (2005) or in the Intergovernmental Panel on Climate Change. However, we present both values for the entire and inner tropics to allow for an 65 easy comparison to other studies. The relative magnitude of the adjusted SWV forcing with respect to the aerosol forcing increases approximately linearly until September 1992 and then reaches a constant values of around $2.5 \%$ for the readout at the tropopause and $4 \%$ percent for the readout at the 70 TOA (Fig. 15b). 

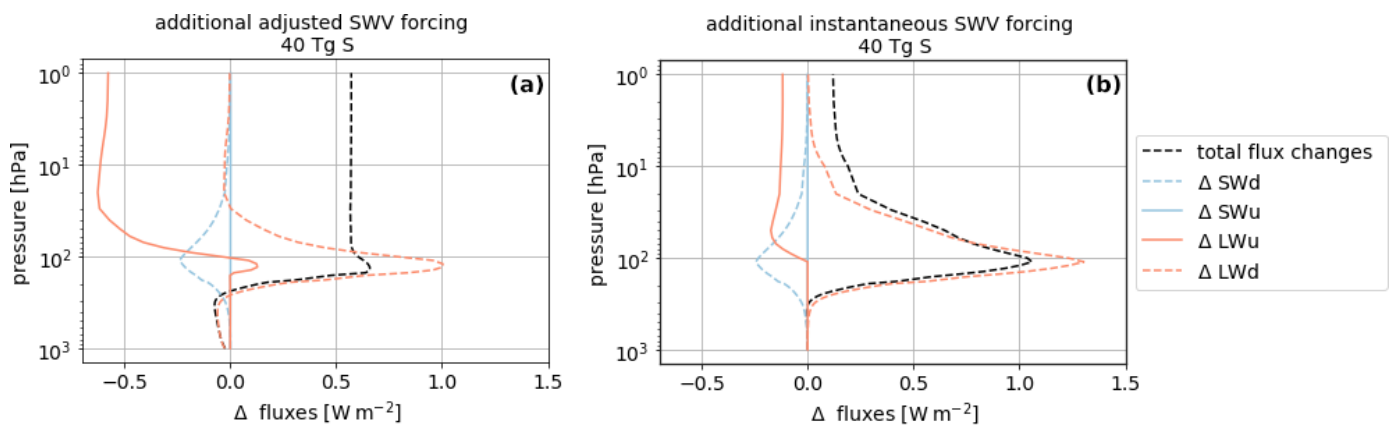

Figure 12. SW and LW contributions to the total adjusted SWV radiative forcing in the tropical stratosphere $[-5,5]^{\circ}$ latitude for November 1992 of the $40 \mathrm{Tg} \mathrm{S}$ eruption. The upward fluxes are in solid lines and positive upward; the downward fluxes are in dashed lines and positive downward. The differences between the perturbed and unperturbed equilibrium states are shown. Panel (a) indicates adjusted forcing and (b) indicates instantaneous forcing.

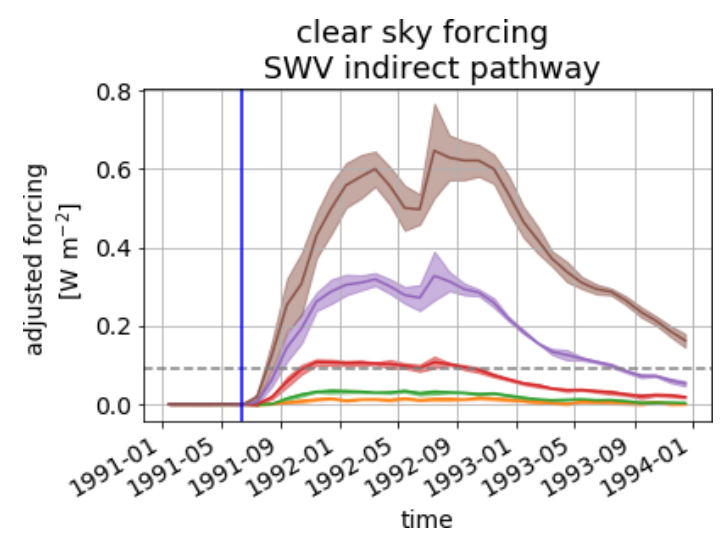

Figure 13. Time evolution of the TOA adjusted clear-sky forcing in the tropical region $[-5,5]^{\circ}$ latitude for the ensemble mean SWV increases caused by all eruption strengths. The blue line marks the eruption time; the dashed gray line shows the threshold up to which deviations in radiative fluxes can be caused by internal variability. Shaded areas indicate the flux anomaly range originating from the standard deviations of the SWV profiles and are plotted to visualize the signal range.

\section{Discussion}

\subsection{Magnitude of SWV increases due to indirect volcanic mechanism}

In general, the annual cycle of the tropical tropopause tem${ }_{5}$ peratures accounts for a variation of the SWV content of $\pm 1.4 \mathrm{ppmv}$ around the mean background at $110 \mathrm{hPa}$ in SAGE II data of the early 1990s (Mote et al., 1996) and $\pm 1.0-1.3$ ppmv based on the SPARC Data Initiative multiinstrument mean (SDI MIM) at $100 \mathrm{hPa}$ in 2005-2010 (Davis 10 et al., 2017). In MPI-GE, the variation in the SWV tape recorder signal at the same height reaches up to $\pm 1.1 \mathrm{ppmv}$. This is in accordance with the SDI MIM and only slightly lower than the SAGE II data. The slightly higher values reported for early 1990 fall into the era of the Mt. Pinatubo eruption, however, and may be increased compared to the multiyear mean due to an amplification of the seasonal signal by the presence of the aerosol layer. This effect led to maximum deviations of up to $\pm 1.6 \mathrm{ppmv}$ in the $10 \mathrm{Tg} \mathrm{S}$ scenario of the EVAens simulations. In the case of volcanic perturbations, the alterations in SWV content caused by the indirect temperature controlled entry mechanism via tropopause warming after volcanic eruptions can surpass the SWV variations due to the annual cycle. In our simulations, deviations of more than $\pm 1.1 \mathrm{ppmv}$ are produced in the simulations for emissions equal to or larger than a $10 \mathrm{Tg} \mathrm{S}$ eruption, which is an upper bound of the emission estimate for the Mt. Pinatubo eruption (Timmreck et al., 2018). The SWV anomaly caused by the $2.5 \mathrm{Tg} \mathrm{S}$ eruption is comparable to changes caused by the quasi-biennial oscillation (QBO), which are [0.160.32] ppmv according to the regression analysis by Dessler et al. (2013), whereas the $10 \mathrm{Tg} \mathrm{S}$ has an impact stronger than the changes in the BDC (maximum $0.65 \mathrm{ppmv}$ ). In climate change studies, the stratospheric water vapor is also affected by doubled $\mathrm{CO}_{2}$ concentrations. The sea surface temperature (SST) increase leads to a consequent atmospheric humidity increase, amounting up to $6 \%-10 \%$ in the stratosphere, with values exceeding $10 \%$ in the lower stratosphere (Wang et al., 2020). These changes of SWV due to increased $\mathrm{CO}_{2}$ levels are comparable to increases caused by the smaller eruptions of 2.5 and $5 \mathrm{Tg}$ S. However, the SWV changes due to volcanic eruptions are only temporary.

\subsection{Comparison to studies based on observations and reanalysis data}

While our model study has the advantage that the large ensemble size allows determining the statistical significance of 45 SWV increases and the spread of responses to a volcanic eruption due to internal variability of the Earth system, a model study is always limited by the ability of the model to represent the Earth system realistically. Individual models may differ in the parameterization of convection, the entry of 50 


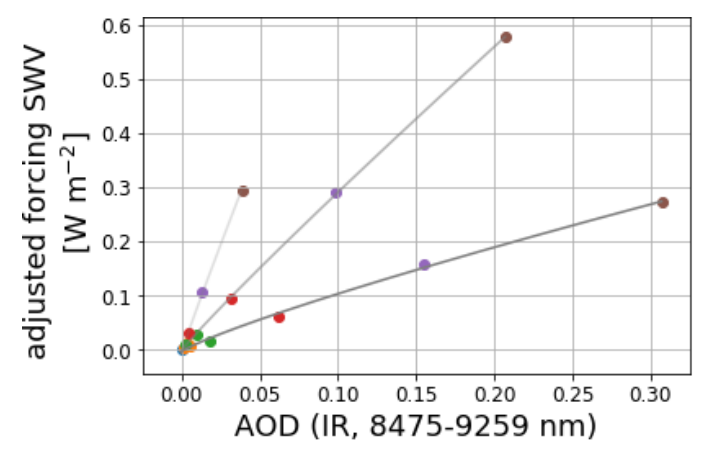

\begin{tabular}{lll}
\hline & 1991 fit with & \\
& 0.7569 AOD $^{0.8505}$ & -0.003 \\
& 1992 fit with & \\
& 2.5461 AOD $^{0.9405}$ & -0.001 \\
& 1993 fit with & \\
& 6.7287 AOD $^{0.9545}$ & -0.004 \\
- & $0 \mathrm{Tg} \mathrm{S}$ & \\
- & $2.5 \mathrm{Tg} \mathrm{S}$ \\
- & $5 \mathrm{Tg} \mathrm{S}$ \\
- & $10 \mathrm{Tg} \mathrm{S}$ \\
- & $20 \mathrm{Tg} \mathrm{S}$ \\
- & $40 \mathrm{Tg} \mathrm{S}$
\end{tabular}

Figure 14. Yearly averages of adjusted forcing due to the additional SWV as a function of AOD (IR, 8475-9259 nm) for the 3 examined years (1991-1993). A power function fit for each year with a corresponding equation is shown.
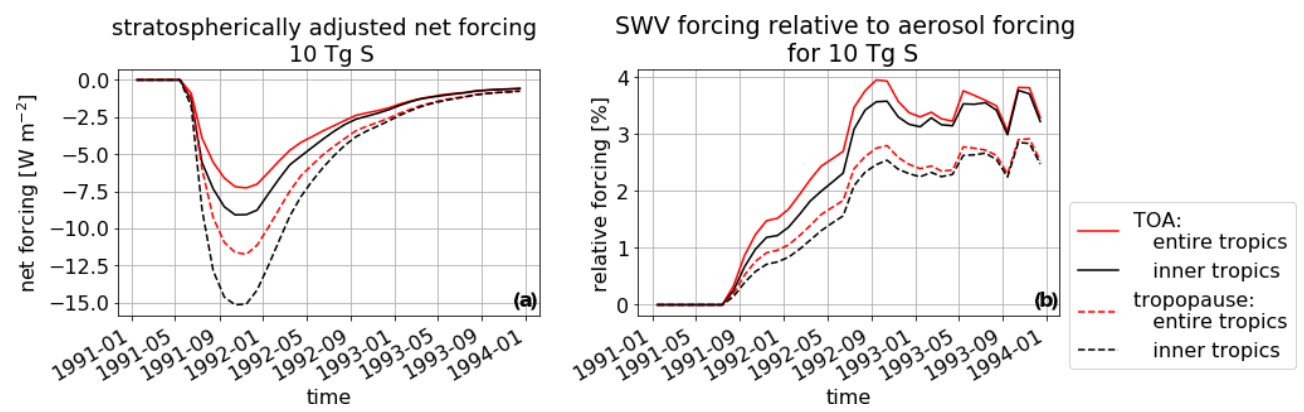

Figure 15. (a) Time evolution of the tropical aerosol forcing for the $10 \mathrm{Tg} \mathrm{S}$ run as calculated using the double radiation call in MPI-ESM. The forcing is evaluated for the inner and entire tropics at the tropopause and the TOA. (b) Time evolution of the percentage of aerosol forcing counterbalanced by the SWV forcing in the inner and entire tropics.

water vapor into the stratosphere and tropopause height. The aerosol profiles used in this study are artificial in the case of EVAens and will include uncertainties of the retrieval in the case of the PADS data set. As our results are therefore 5 at first only representative of the model used in our study, a comparison to results based on or derived from observational evidence of SWV changes after volcanic eruptions is desirable.

During the Mt. Pinatubo period, observations of SWV are 10 scarce, especially as solar occultation measurements by the Halogen Occultation Experiment (HALOE) and SAGE II suffered from aerosol interference in this time period. Therefore, the data usage is discouraged (e.g., Fueglistaler et al., 2013). Although Fueglistaler et al. (2013) mention "anoma15 lously large anomalies" of SWV values shortly after the Mt. Pinatubo eruption in SAGE II data, they also warn that the measurements may be biased by aerosol artifacts since the SWV signal is not present in the HALOE data. However, in the Boulder balloon data, a 1-2 ppmv increase of SWV 20 at $24-26$ and $18-20 \mathrm{~km}$ levels is registered for 1992 (Oltmans et al., 2000). Most likely due to additional contribution from, e.g., methane oxidation or ENSO signals, the maximum increase is slightly larger than the 1.0-1.2 ppmv shown for the tropical region in Fig. 7 or the value of approximately ${ }_{25} 0.5 \mathrm{ppmv}$ at $70 \mathrm{hPa}$ at corresponding latitude (compare Ap- pendix Fig. F1). Santer et al. (2003) discuss a global warming of the lower stratosphere caused by the eruption of Mt. Pinatubo amounting to $0.75-1.5 \mathrm{~K}$ as measured by MSU. Angell (1997) reports the stratospheric warming due the eruption of Mt. Pinatubo based on radiosonde data. The warmest seasonal anomaly in the $100-50 \mathrm{hPa}$ layer at the Equator reached $(2.0 \pm 0.8) \mathrm{K}$, where we find $1.8 \mathrm{~K}$ for the $5 \mathrm{Tg} \mathrm{S}$ and $5.2 \mathrm{~K}$ for the $10 \mathrm{Tg} \mathrm{S}$ scenario in October-NovemberDecember (OND) 1991. The corresponding SWV increase at background levels of $4.5-5 \mathrm{ppmv}$ can be estimated to be 1.13-1.3 ppmv based on a $12 \%$ increase of SWV per Kelvin. These values are consistent with our findings (Fig. 7). As more regression analyses exist based on reanalysis data, we now compare our results not directly to observations but to the outcome of two regression analysis studies of SWV entry fed by the reanalysis input by Dessler et al. (2014) and Tao et al. (2019). Dessler et al. (2014) studied the different contributors to SWV entry at $82 \mathrm{hPa}$ slightly above the tropical tropopause in their model by using a regression analysis on data output from a trajectory model fed by 45 Modern-Era Retrospective analysis for Research and Applications (MERRA) reanalysis input (Rienecker et al., 2011). They found a maximum increase of $0.34 \mathrm{ppmv}$ in the residual, which partially overlapped the AOD increase caused by the Mt. Pinatubo eruption. This value is lower than our 50 
finding of up to $(0.8-1.1)$ ppmv increase in the first and second post-eruption years. Our higher value may be explained by the different quantification approaches: whereas Dessler et al. (2014) indirectly quantified the SWV increase ${ }_{5}$ due to Mt. Pinatubo in the residuals after subtracting contributing terms like the BDC, we directly quantified the additional SWV entry by taking the difference between the MPI-GE historical ensemble with volcanic aerosol and the EVAens control run. This allowed us to avoid the subtrac10 tion of SWV entry caused by the volcanic eruption but attributed to other sources. For example, in the Dessler et al. (2014) study, the BDC term is described by the heating in the $82 \mathrm{hPa}$ region, but part of this may be caused by the presence of the volcanic aerosol layer. Our method also elimi15 nates other sources of SWV that may have caused the SWV increase prior to the Mt. Pinatubo eruption in the residual of Dessler et al. (2014). Additionally, the tropopause in our historical simulation is located at pressures larger than $100 \mathrm{hPa}$. Dessler et al. (2014) report that $82 \mathrm{hPa}$ is slightly above the 20 tropopause. Their possibly higher-lying tropopause may also explain part of the difference. Tao et al. (2019) use MERRA2 (Gelaro et al., 2017), the Japanese 55-year Reanalysis (JRA-55) (Kobayashi et al., 2015) and ERA-Interim (Dee et al., 2011) reanalysis data for the Mt. Pinatubo eruption 25 in their trajectory model. The SWV increase attributed to the volcanic eruption ranges between $0.4 \mathrm{ppmv}$ (ERA-Interim) and 0.8 ppmv (MERRA-2 and JRA-55). Only MERRA-2 explicitly accounts for the volcanic aerosol (Fujiwara et al., 2017): their corresponding $0.8 \mathrm{ppmv}$ SWV increase is in so good agreement with the SWV increases found in the first post-eruption year in our historical simulations, although our SWV increase in the second post-eruption year of $1.1 \mathrm{ppmv}$ is larger. As analyzed in Sect. 3.5, this higher increase is mainly caused by the height of the aerosol layer with re${ }_{35}$ spect to the cold point. Since the aerosol profiles are imported on fixed pressure levels, without prescribing the distance between the tropopause and the aerosol layer, and the tropopause heights differ amongst various models, the comparison between different studies and models would be facil${ }_{40}$ itated if not only the total volcanic forcing but also the heating in the region were reported when quantifying and comparing volcanically induced SWV increases. A tropopause located at larger pressure in the second post-eruption summer in the reanalysis data could explain the differences be45 tween the maximum values of 0.8 ppmv by Tao et al. (2019) using the MERRA-2 reanalysis and our results amounting up to $1.1 \mathrm{ppmv}$ in the second post-eruption summer, as it would lead to a lower heating rate in the cold-point region and consequently a reduced water vapor entry compared to ${ }_{50}$ the control years. Additionally, our model does not include interactive chemistry- $\mathrm{H}_{2} \mathrm{O}$ sinks could reduce the amount of water vapor and especially the buildup in the second posteruption summer. However, Löffler et al. (2016) also found a stronger SWV increase in the second post-eruption sum${ }_{55}$ mer when investigating the perturbations of stratospheric wa- ter vapor using nudged chemistry-climate model simulations with prescribed aerosol for the Mt. Pinatubo eruption. The SWV increases for the Mt. Pinatubo eruption reach values of up to $35 \%$ compared to the unperturbed run in the inner tropical average. Thus, our finding of an increase of $25 \%$ above the unperturbed levels for the historical simulations (compare Fig. B1) lies between the estimates from reanalysis data by Tao et al. (2019) and the chemistry-climate studies by Löffler et al. (2016). In EVAens, where the temporal evolution of the extinction profile does not lead to as drastic changes in the vertical shape as in the PADS forcing data set, the temporal evolution of the increase in SWV is similar to the evolution found by Tao et al. (2019), with only one prominent maximum. Maximum values of SWV increase are in the range of 0.3 and $1.1 \mathrm{ppmv}$ for the 5 and $10 \mathrm{Tg}$ S EVAens runs - cover- 70 ing the estimated sulfur emission range of Mt. Pinatubo and in agreement with Tao et al. (2019).

\subsection{SWV contributions due to the indirect volcanic and direct volcanic injection}

Unlike the direct volcanic mechanism, the indirect volcanic 75 pathway is active for the entire lifetime of the volcanic aerosol in the lower stratosphere, whereas the direct volcanic injection is a singular event. There is no study known to us comparing the SWV entry due to both events within one framework. Although up to $80 \%$ of the eruption vol- 80 ume can be water vapor (Coffey, 1996), rapid condensation can remove $80 \%-90 \%$ of this humidity on the way to the stratosphere (Glaze et al., 1997). There are only a few cases of direct volcanic injections reported, which cover relatively small eruption events. The water vapor within the eruption 85 column reaching the stratosphere did not lead to elevated SWV above background for more than a week locally in the few cases reported, i.e., the eruption of Kasatochi (in 2008) with maximum SWV content of 9 ppmv (Schwartz et al., 2013) lasting for around $1 \mathrm{~d}$, the eruption of Cal- 90 buco (2015) with 10 ppmv values for approximately a week (Sioris et al., 2016a) and the eruption of Mt. St. Helens with $(64 \pm 4)$ ppmv (Murcray et al., 1981) detectable above background for around a week but only on a local and not a global scale. In the case of the Mt. Pinatubo eruption, the model 95 estimates for the direct volcanic injection tended to have a larger range and maximum values than the estimates based on observational data (Joshi and Jones, 2009). In contrast, the indirect volcanic pathway allows for slower but more continuous, raised stratospheric water vapor levels ultimately 100 spreading throughout the globe but with lower peak values. These enhanced SWV levels are detectable in our ensemble mean even years after the actual volcanic eruption if the emitted sulfur amount is larger than $10 \mathrm{Tg}$ S. Depending on the explosivity of the volcano, the relative contributions of the 105 direct and indirect volcanic injection mechanisms to SWV increases should change: for small eruptions, the direct volcanic injection will lead to a relatively high increase in SWV, 
which is short lived and spatially confined. For the larger eruptions, this short-lived SWV enhancement is followed by a relatively stable increase of SWV which spreads throughout the entire globe, dominating the SWV increase due to the 5 volcanic eruption.

\subsection{SWV forcing}

In our simulations, the stratospherically adjusted forcing caused by the increase of SWV in the tropical region amounts to maximally $2.5 \%$ to $4 \%$ of the tropical aerosol forcing 10 over the time frame for the $10 \mathrm{Tg} \mathrm{S}$ eruption. However, although a decline of the tropical forcing within the 3-year time frame is found, the forcing around the complete globe will last longer than the impact of the volcanic aerosols. The decline in tropical stratospheric water vapor is caused by its 15 transport to the poles by the BDC, leading to a regional shift of the location of the SWV forcing (see Fig. F1). Forster and Shine (2002) found the polar SWV forcing to be 2.5 times stronger than the tropical forcing: since in the polar region the tropopause height is lower and the water vapor content 20 is generally lower, SWV increases of the same magnitude have a much larger impact there than in the tropical region. Based on the factor of 2.5, the $40 \mathrm{Tg} \mathrm{S}$ run 1993 values would cause an adjusted forcing of up to $0.5 \mathrm{~W} \mathrm{~m}^{-2}$ in the polar region, whereas the aerosol forcing is back to the levels of the ${ }_{25} 2.5 \mathrm{Tg} \mathrm{S}$ run by 1993 . This shift in relative magnitude is one of the factors contributing to the positive TOA imbalance at the end of 1993 (for 20 and $40 \mathrm{Tg}$ S in Fig. 2).

For the eruption of Mt. Pinatubo, with $(7.5 \pm 2.5) \mathrm{Tg} \mathrm{S}$ emitted, earlier estimates of SWV forcing exist. Joshi and ${ }_{30}$ Shine (2003) calculated the global SWV forcing to be $0.1 \mathrm{~W} \mathrm{~m}^{-2}$. Our $10 \mathrm{Tg} \mathrm{S}$ adjusted forcing results of up to $0.11 \mathrm{~W} \mathrm{~m}^{-2}$ are nearer to the estimate by Joshi and Shine (2003) than our $5 \mathrm{Tg} \mathrm{S}$ results of up to $0.03 \mathrm{~W} \mathrm{~m}^{-2}$. In 1992, the adjusted forcing in the inner tropics lies between [0.02$\left.{ }_{35} 0.03\right] \mathrm{W} \mathrm{m}^{-2}$ for the $5 \mathrm{Tg} \mathrm{S}$ and $[0.06-0.11] \mathrm{W} \mathrm{m}^{-2}$ for the $10 \mathrm{Tg} \mathrm{S}$ scenarios. The better agreement of our $10 \mathrm{Tg} \mathrm{S}$ adjusted SWV forcing with Joshi and Shine (2003) value for the Mt. Pinatubo SWV forcing can be attributed to two points: first, the form and location of the forcing profile with respect 40 to the cold point is crucial when comparing model results of increased SWV levels and the consequent changes in SWV forcing (s. Sect. 3.5). This may contribute to differences between our values and the ones in the Joshi and Shine (2003) analysis. Second, the polar forcing will be stronger than the 45 tropical forcing which was calculated with konrad. Using the ratio of polar forcing to tropical forcing by Forster and Shine (2002), the polar estimate would be $[0.05-0.08] \mathrm{W} \mathrm{m}^{-2}$ for $5 \mathrm{Tg} \mathrm{S}$ and [0.15-0.28] $\mathrm{W} \mathrm{m}^{-2}$ for $10 \mathrm{Tg} \mathrm{S}$.

In their study on direct volcanic SWV entry for the 50 Krakatau eruption, Joshi and Jones (2009) found a LW forcing of $+(0.33 \pm 0.09) \mathrm{W} \mathrm{m}^{-2}$ for a direct volcanic entry above $100 \mathrm{hPa}$ of $1.5 \mathrm{ppmv}$ using the downward TOA heat flux, climate feedback parameter and near-surface tem- perature changes. They chose a relatively high estimate of SWV increase, which would approximately correspond to 55 the SWV increases in our $20 \mathrm{Tg}$ S eruption run. As the TOASW contribution to our forcing is negligible (see Fig. 12), a comparison to our total forcing is possible. The corresponding value of [0.21-0.33] $\mathrm{W} \mathrm{m}^{-2}$ is in the lower part of the range found by Joshi and Jones (2009), which is likely 60 caused mainly by the restriction of our study to the tropical region.

Krishnamohan et al. (2019) also mentioned the contribution of aerosol induced SWV changes to the flux changes at the TOA in a geoengineering study; however, they did not 65 explicitly calculate it. The amount of shortwave forcing they attribute to additional SWV is much higher than our value and also positive. Presumably these differences are caused by the forcing including tropospheric adjustments and using $\mathrm{CO}_{2}$ concentrations equal to twice the amount of their pre- 70 industrial control run and thus cannot be compared to our study.

In order to put the adjusted radiative SWV forcing due to the indirect volcanic pathway into a broader context, we compare it with SWV forcing due to anthropogenic $\mathrm{CO}_{2}$ and 75 methane releases: the rate of radiative forcing increase due to $\mathrm{CO}_{2}$ in the $2000 \mathrm{~s}^{2}$ reached values of almost $0.03 \mathrm{~W} \mathrm{~m}^{-2} \mathrm{yr}^{-1}$ and a total of $(1.82 \pm 0.19) \mathrm{W} \mathrm{m}^{-2}$ for the 1750 to 2011 time frame, whereas the additional radiative forcing due to methane in the same time frame is $(0.48 \pm 0.05) \mathrm{W} \mathrm{m}^{-2}{ }_{80}$ (Myhre et al., 2013) ${ }^{3}$. The forcing caused by the SWV entering the stratosphere via the indirect volcanic entry mechanism exceeds the yearly increase of forcing due to $\mathrm{CO}_{2}$ in the 2000s starting with the $5 \mathrm{Tg} \mathrm{S}$ run. The peak adjusted tropical SWV forcing for the $40 \mathrm{Tg} \mathrm{S}$ scenario amounts to 85 one-third of the total $\mathrm{CO}_{2}$ forcing (due to the accumulated emissions from 1750 to 2011) and is larger than the forcing due to methane emissions for the same period.

\subsection{Predictability of responses}

The increases in cold-point temperature and SWV are de- 90 layed events. Time is required for it to build up the signals as the aerosols warm the cold-point region, allowing more water vapor transit into the stratosphere. An approximately stable phase with fluctuations due to the seasonal cycle is attained a couple of months after eruption. The cold-point 95 warming has stabilized. The SWV forcing is mainly determined by the additional SWV entering the stratosphere each month as the tropopause region is the region in which $\mathrm{WV}$ has the strongest radiative effect. The corresponding buildup of tropical SWV forcing due to an accumulation of SWV in 100 the stratosphere is therefore counteracted by the transport to higher altitudes and to the polar region by the BDC. Due to

\footnotetext{
${ }^{2}$ Atmospheric $\mathrm{CO}_{2}$ concentration increased from $(278 \pm 2)$ to (390.5 \pm 0.2$)$ ppmm.

${ }^{3}$ Methane concentration increased from $(722 \pm 25)$ to $(1803 \pm 2) \mathrm{ppb}$.
} 
the transient character of the processes - the buildup of the forcing and the consequent decline as well as the time shift between effect and response - our analysis showed that a linear relationship between AOD and cold-point warming, or ${ }_{5} \mathrm{SWV}$, cannot be determined for the entire era after the volcanic eruption. Time phases have to be considered as well to account for the resulting hysteresis. Other parameters additionally constrain the cold-point warming and SWV response. The season during which the eruption occurs will 10 influence the impact of the aerosols: the CP warming will be most effective during the peak times of the tape recorder signal around September. Each volcanic eruption is different and parameters like the eruption location, amount of emitted sulfur and specifically the location of the aerosol layer will 15 have a massive influence both on cold-point warming and SWV entry/forcing. Feedbacks like the SWV forcing in the TTL will enhance the CP warming and lead to higher SWV forcing at same AODs eventually before the aerosols fall out. Nevertheless, approximately a power function relationship ${ }_{20}$ of form $a \mathrm{AOD}^{b}+c$ can be found in our simulations for $\mathrm{CP}$ warming and SWV forcing with respect to IR AOD after the volcanic eruptions when taking yearly averages. These results, however, must be interpreted with care, and the derived formulas are only applicable for tropical eruptions occurring 25 in June and reaching to similar heights in the stratosphere. Generally, the knowledge - both of the respective CP warming in the inner tropics for a specific volcanic eruption and the respective background SWV in the cold-point region - allows for a relatively accurate prediction of the inner tropical ${ }_{30}$ increases in SWV levels when using a $12 \%$ SWV increase per Kelvin warming in the mean $\mathrm{CP}$ values.

\section{Conclusion and outlook}

Our study of EVAens and the historical simulations led us to draw the following conclusions:

1. The analysis of the ensemble runs showed the difficulty to extract the volcanic signal in the SWV if only individual observations are available, as internal variability of SWV in the control run could produce SWV values as large as the variation found for some of the $10 \mathrm{Tg} \mathrm{S}$ ensemble members in our simulations. Ensemble mean SWV increases are already significant $(t$ test with $p=0.05$ ) in the $2.5 \mathrm{Tg} \mathrm{S}$ eruption.

2. The increase in stratospheric water vapor does not remain constant throughout year but can vary with the seasons. An amplification of the seasonal cycle could be observed, especially in the 20 and $40 \mathrm{Tg}$ S scenarios.

3. The average $\mathrm{WV}$ at the cold point entering the stratosphere after volcanic eruptions can be approximated with only minor errors using the mean saturation water vapor pressure over ice at the respective average tropical cold-point temperature for all investigated aerosol profiles of EVAens. When given a base value of an unperturbed atmospheric state, a $12 \%$ SWV increase per Kelvin increase in cold-point temperature is a good first estimate for eruption strengths up to $40 \mathrm{Tg} \mathrm{S}$.

4. The comparison of the idealized EVAens simulations and MPI-GE historical simulations of Mt. Pinatubo show that neither the simulated TOA radiative imbalance nor the estimated amount of emitted stratospheric sulfur suffice to constrain the SWV increases. However, the aerosol layer shape and height with respect to the tropopause play a crucial and dominating role when estimating the SWV increases.

5. The adjusted tropical forcing caused by the additional SWV lasts longer than the forcing caused by the aerosol 6 layer itself, and its contribution to the total volcanic forcing grows with time as the aerosols fall out. For the 20 and the $40 \mathrm{Tg} \mathrm{S}$ scenarios, the TOA radiative imbalance shows a positive value by the end of the simulation. Part of this positive TOA radiative imbalance can be at- 70 tributed to the forcing by the additional SWV.

6. When considering also the time dependence, a power function relationship of form $a \mathrm{AOD}^{b}+c$ between yearly averaged tropical cold-point warming/adjusted SWV forcing and IR AOD can be deduced. This relationship 75 however only holds for comparable eruptions occurring at the same time of the year in the tropics. Additionally, the final eruption height and aerosol profile shape have to match the ones used within our framework.

Based on our study, follow-up questions for future investi- 80 gations arise. Our study only focuses on the indirect temperature controlled injection and, although other studies focus on the direct injection, no study known to us combines both effects allowing for a direct comparison within a single framework. Using integrated plume models for a combined study would allow the quantification of the entire SWV changes and for an estimation of their relative importance. As we use no interactive chemistry, the $\mathrm{H}_{2} \mathrm{O}$ value determined by us might be overestimating the SWV from the indirect volcanic injection remaining in the stratosphere. A study using interactive chemistry would allow the assessment of the impact of $\mathrm{H}_{2} \mathrm{O}$ sinks on the volcanically induced SWV increase and ozone chemistry. Of particular interest is the impact of the additional $\mathrm{H}_{2} \mathrm{O}$ on the oxidation process of $\mathrm{SO}_{2}$, as well as on sulfate particle formation and growth. A follow-up study on this topic could give a lower boundary estimate for the SWV increases and the changed aerosol lifetime (compare Case et al., 2015, Kilian et al., 2020). Additionally, the mechanism of the indirect volcanic injection has implications beyond that of a volcanic eruption: as geoengineering scenarios 100 also apply sulfur derivatives in the stratosphere, an investigation of the long-term SWV signal within these scenarios may be of interest as well (e.g., Boucher et al., 2017). 


\section{Appendix A: Scaling of different physical parameters altered by the presence of volcanic aerosols}

Following the discussion in Sect. 3.1, 3.2 and 3.6, the graphs for TOA imbalance (Fig. A1), surface temperature (Fig. A2), 5 cold-point temperature changes (Fig. A3) and SWV forcing (Fig. A5) are shown. Each ensemble mean is divided by the mass of emitted sulfur. In the case of the cold-point temperature changes and the SWV forcing, the dependence of monthly mean values of cold-point temperature change and ${ }_{10} \mathrm{SWV}$ forcing is shown as a function of AOD in the IR waveband of $[8475,9259] \mathrm{nm}$ in Figs. A4 and A6.

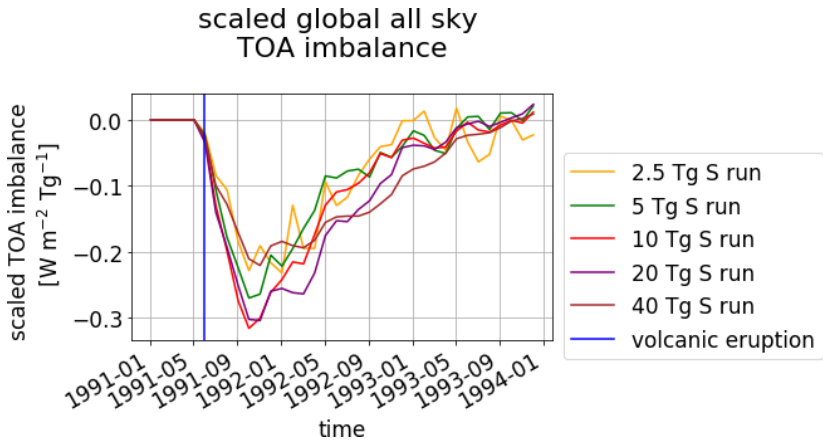

Figure A1. Scaled TOA imbalance for the five volcanically perturbed EVAens runs $(2.5,5,10,20$ and $40 \mathrm{Tg} \mathrm{S})$. The ensemble means are shown. The vertical blue line marks the eruption time. All TOA imbalances are divided by the mass of emitted sulfur.

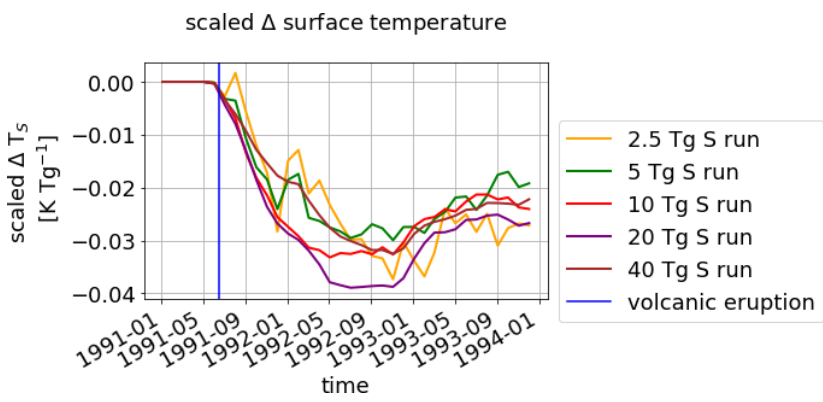

Figure A2. Scaled surface temperature for the five volcanically perturbed EVAens runs $(2.5,5,10,20$ and $40 \mathrm{Tg} \mathrm{S})$. The ensemble means are shown. The vertical blue line marks the eruption time. All surface temperatures are divided by the mass of emitted sulfur.

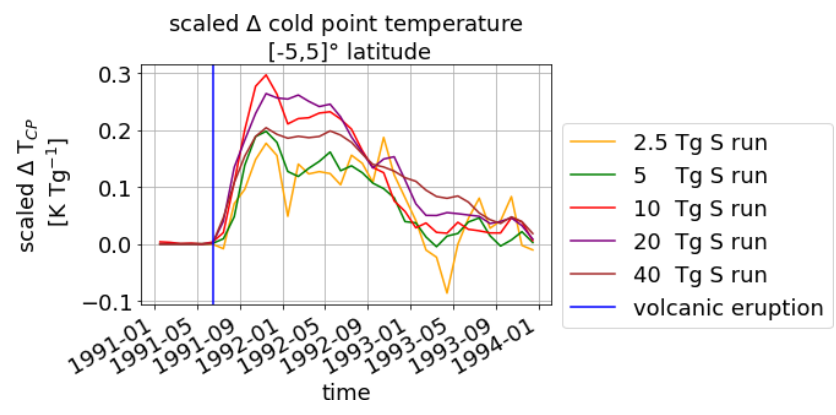

Figure A3. Scaled temporal evolution of the mean CP temperature anomaly. The time of the volcanic eruption is indicated by a vertical blue line. All changes in cold-point temperature are divided by the mass of emitted sulfur.

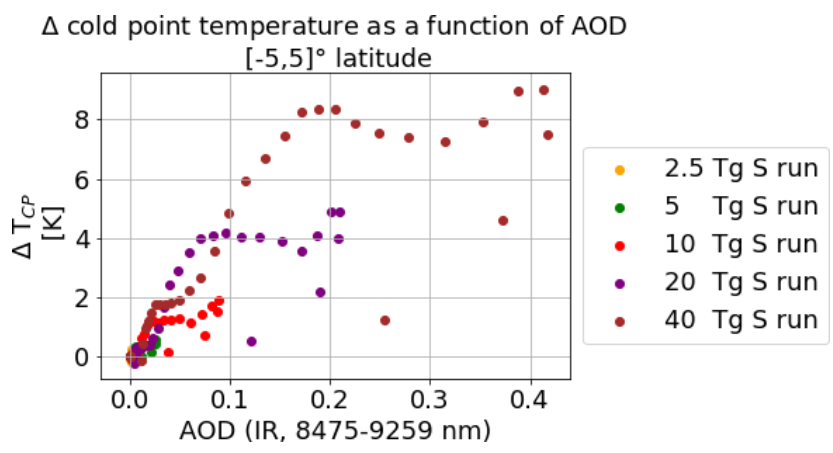

Figure A4. Scatter plot of AOD in the IR waveband (8475$9250 \mathrm{~nm}$ ) and CP temperature anomaly for all time steps in the first 2.5 years after the eruption. 


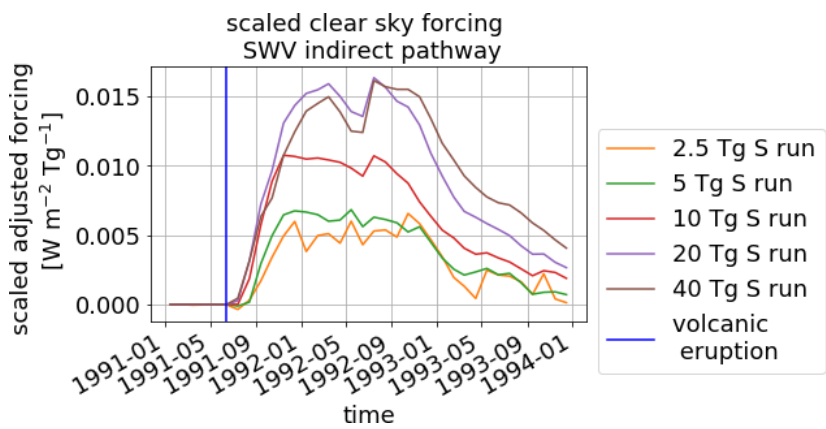

Figure A5. Scaled time evolution of the adjusted clear-sky SW forcing in the tropical region $[-5,5]^{\circ}$ latitude for all eruption strengths. The blue line marks the eruption time. All clear-sky forcings are divided by the mass of emitted sulfur. Incoming fluxes are defined as positive; outgoing fluxes are defined as negative.

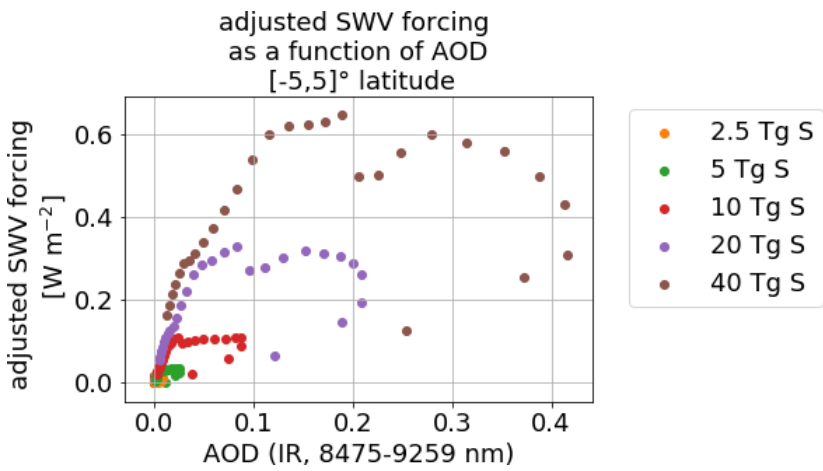

Figure A6. Scatter plot of AOD in the IR waveband (8475$9250 \mathrm{~nm}$ ) and the clear-sky SWV forcing for all time steps in the first 2.5 years after the eruption. 


\section{Appendix B: Percental changes in the tape recorder signal}

Complementary to the plot in Sect. 3.3, we show the differences in water vapor between perturbed and unperturbed states with respect to the unperturbed state in percent.

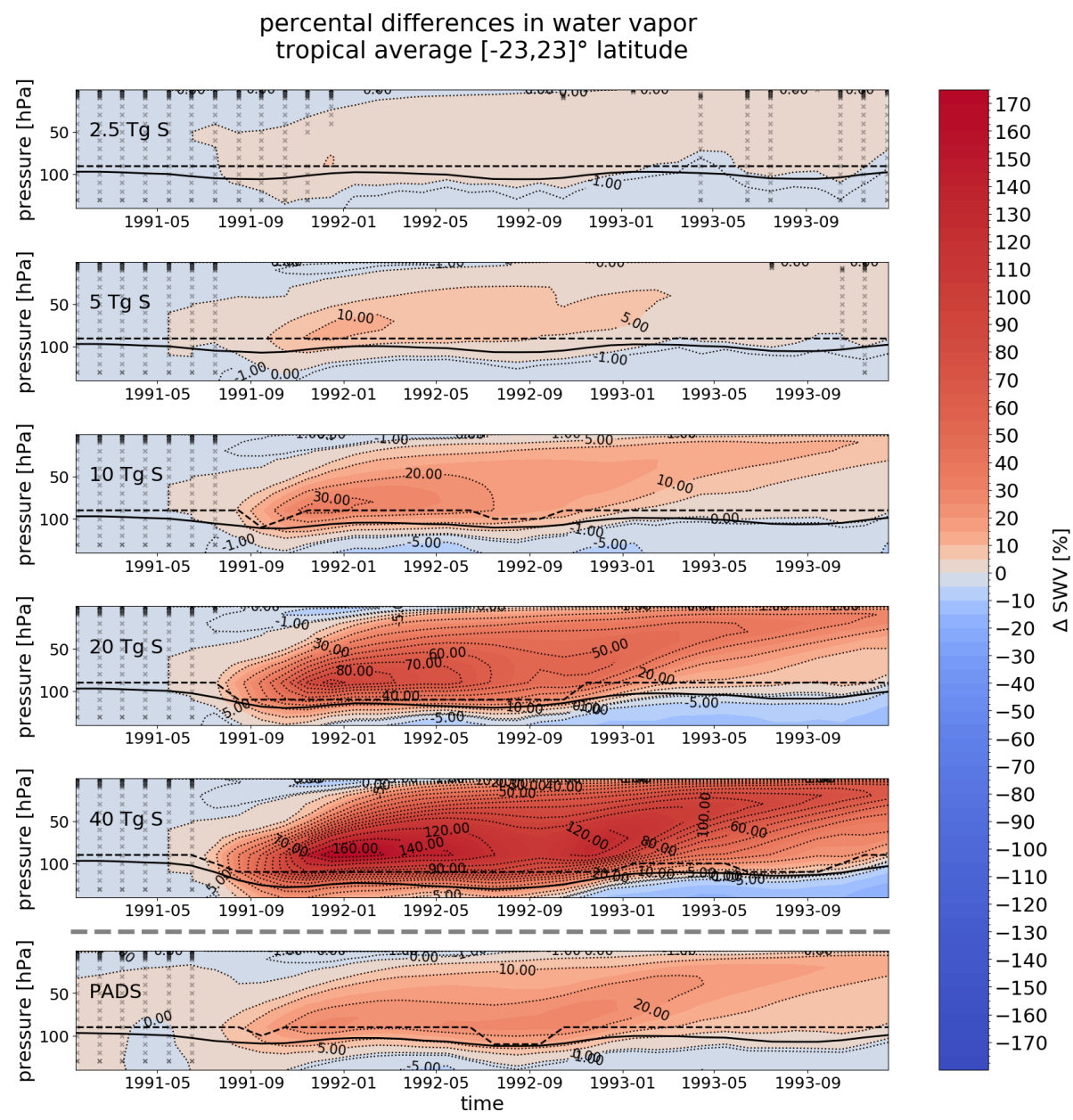

Figure B1. Percental difference in water vapor above $140 \mathrm{hPa}$ in the tropical average over $[-23,23]^{\circ}$ latitude for the pure sulfur injections of EVAens $(2.5,5,10,20$ and $40 \mathrm{Tg}$ S). The lowermost panel shows the MPI-GE historical simulations for Mt. Pinatubo using the PADS forcing data set. The height of the WMO tropopause is indicated by a black line; the cold-point pressure is indicated by a dashed black line. In regions not covered by black crosses, statistically significant differences between stratospheric water vapor values of the perturbed and unperturbed runs ( $t$ test at $p=0.05$ ) were found. 


\section{Appendix C: Intra-ensemble variability in the entire tropics}

Here, we show the complementary plots to those in Sect. 3.4 for the intra-ensemble variability in the entire tropics $\left([-23,23]^{\circ}\right.$ latitude).
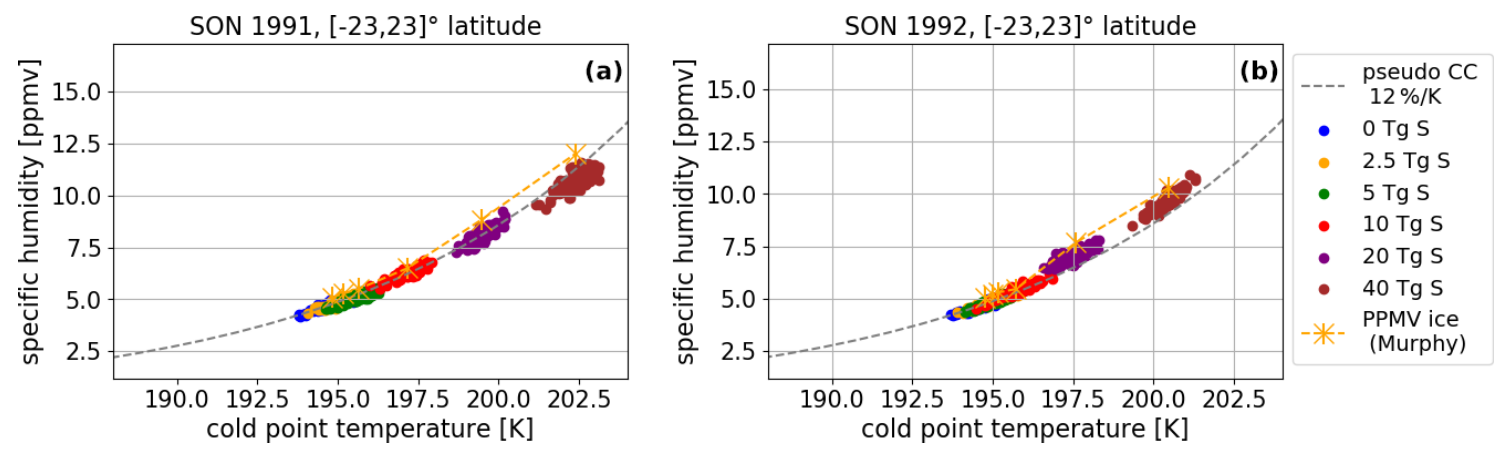

Figure C1. Seasonal averages of specific humidity at cold point as a function of cold-point temperature for SON 1991 (a) and 1992 (b) accounting for the entire tropics. Values for each individual ensemble member are shown as dots for the entire tropics. An approximation (see text) for the Clausius-Clapeyron equation at this temperature range with an $12 \%$ increase of specific humidity per Kelvin is indicated by a dashed gray line. The exact solution for the Clausius-Clapeyron equation over ice by Murphy and Koop (2005) is calculated for the average ensemble cold-point temperatures and pressure and shown in orange. 


\section{Appendix D: Aerosol extinction profiles $\mathbf{- 5 5 0} \mathbf{~ n m}$ solar waveband}

Complementary to the discussion on the infrared extinction profiles in Sect. 3.5, the $550 \mathrm{~nm}$ solar waveband is shown in the following plots.

aerosol extinction (SW, $550 \mathrm{~nm}$ )
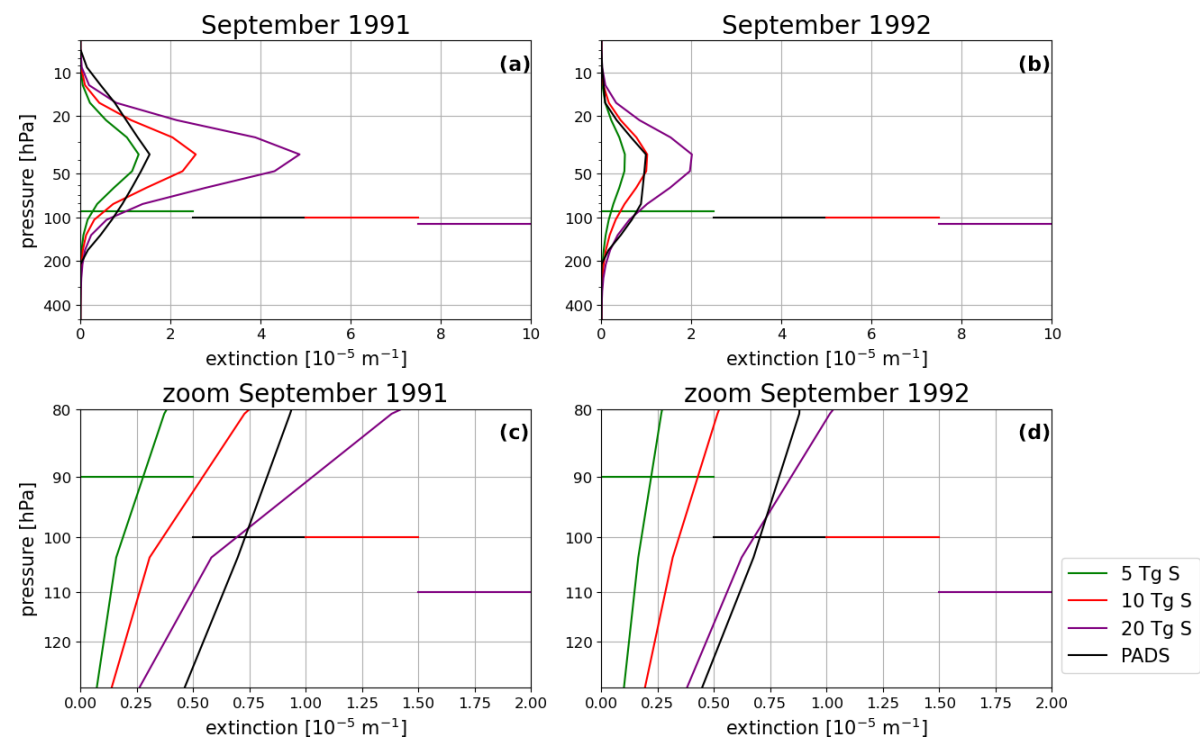

Figure D1. Tropical average of the aerosol extinction profile in the $550 \mathrm{~nm}$ solar waveband for the EVA forcing corresponding to 5 , 10 and $20 \mathrm{Tg} \mathrm{S}$ as well as the PADS forcing for the Mt. Pinatubo eruption.

5

\section{Appendix E: SWV forcing - SW component}

Figure E1 shows the very small contribution of the SW component to the total adjusted SWV forcing presented in Sect. 3.6.

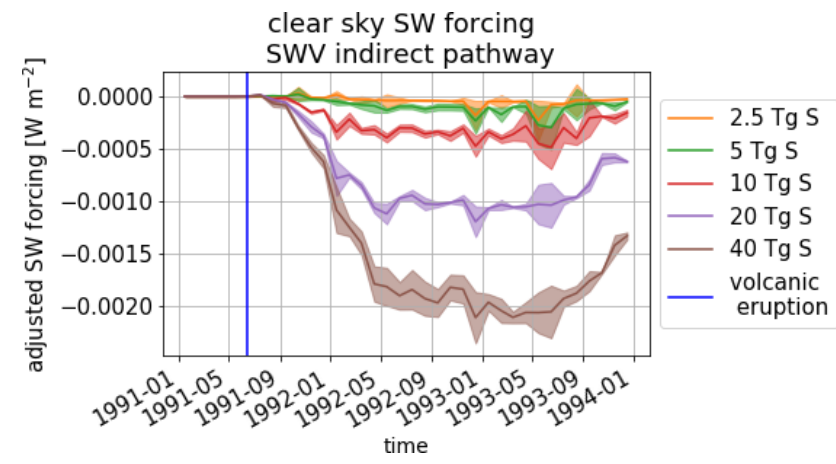

Figure E1. Time evolution of the SW component to the adjusted clear-sky forcing in the tropical region at $[-5,5]^{\circ}$ latitude for the ensemble mean SWV increases caused by all eruption strengths. The blue line marks the eruption time. The flux range originating from the standard deviations of the SWV profiles is plotted to visualize the signal range. 
The total forcing and its SW component for the cloudy-sky case as discussed in Sect. 3.6 is shown in Fig. E2.
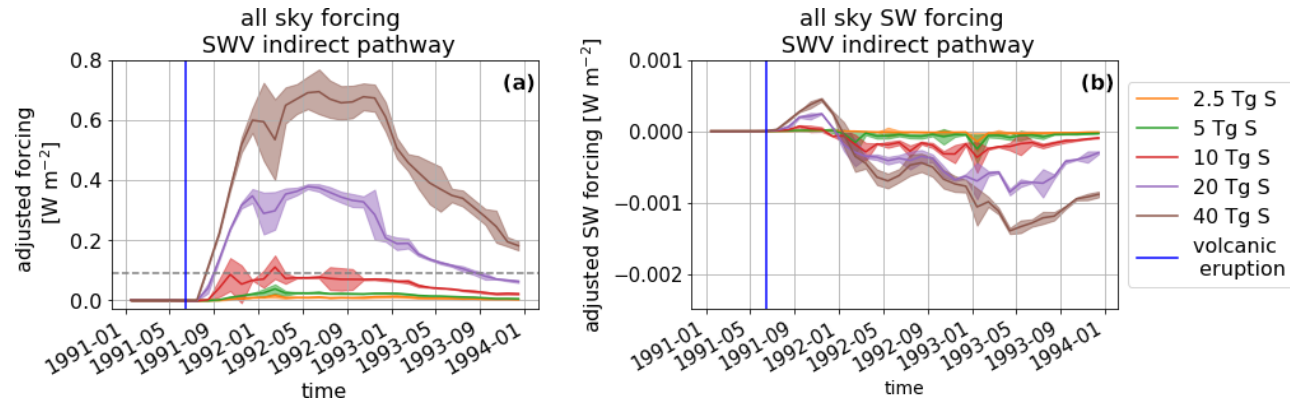

Figure E2. Time evolution of the (a) total and (b) SW component to the adjusted all-sky forcing in the tropical region at $[-5,5]^{\circ}$ latitude for the ensemble mean SWV increases caused by all eruption strengths. The blue line marks the eruption time. The flux range originating from the standard deviations of the SWV profiles is plotted to visualize the signal range.

\section{Appendix F: Global spread of the stratospheric water vapor}

${ }_{5}$ Figure F1 shows the spread of the additional SWV around the globe as mentioned in the Discussion (Sect. 4.4).

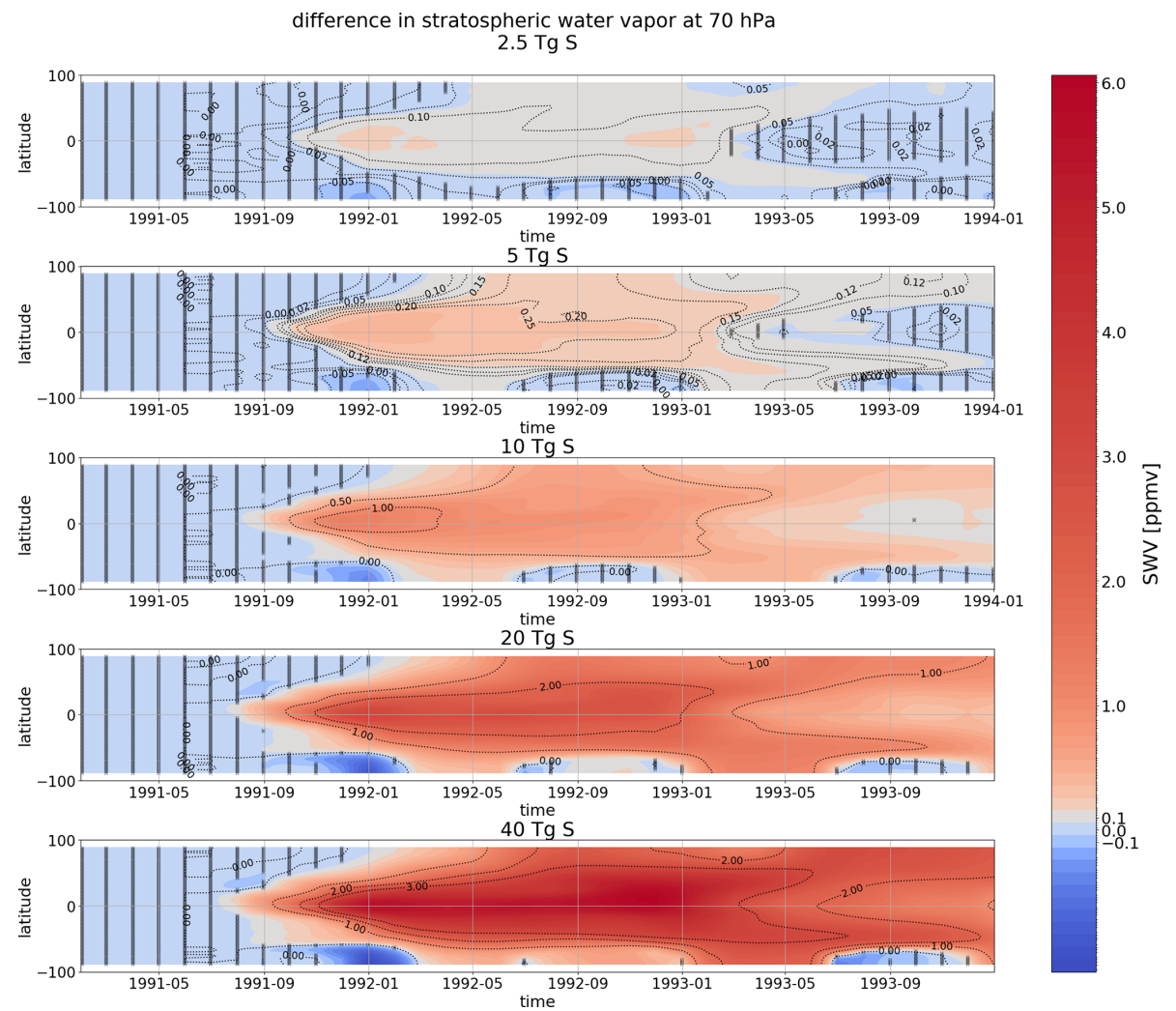

Figure F1. Difference in stratospheric water vapor content at $70 \mathrm{hPa}$ as a function of time and latitude. Black crosses mark the regions of statistical significance of the data (Mann-Whitney $U$ test at $p=0.05$ ). 
Code and data availability. Primary data and scripts used in the analysis that may be useful in reproducing the author's work are archived by the Max Planck Institute for Meteorology and can be obtained via https://pure.mpg.de/pubman/faces/ 5 ViewItemOverviewPage.jsp?itemId=item_3270686 (Kroll, 2020). A more comprehensive description of EVAens is provided by Azoulay et al. (2021). Further information was archived by the Max Planck Institute for Meteorology under http://hdl.handle.net/ 21.11116/0000-0007-8B38-E (Azoulay et al., 2021). The 1-D RCE 10 model konrad is available online under https://doi.org/10.5281/ zenodo.2597967 (Kluft and Dacie, 2019).

Author contributions. CAK, CT and HS designed the study. CAK conducted the analysis/investigation and wrote the paper. SD contributed to the development of the methodology to calculate the ${ }_{15}$ SWV forcing with konrad and the interpretation of the corresponding result. AA set up the EVAens simulations. CT, SD and HS contributed to the writing of the paper.

Competing interests. The authors declare that they have no conflict of interest.

20 Special issue statement. This article is part of the special issue "The Model Intercomparison Project on the climatic response to Volcanic forcing (VolMIP) (ESD/GMD/ACP/CP inter-journal SI)". It is not associated with a conference.

Acknowledgements. Sally Dacie and Clarissa Alicia Kroll were/are 25 members of the International Max Planck Research School (IMPRS). The data were processed using CDO (https://code.mpimet. mpg.de/projects/cdo/embedded/cdo.pdf, last access: 20 November 2020) and using the computing facilities at the Deutsche Klimarechenzentrum (DKRZ). We thank Lukas Kluft for advising us 30 on the usage of the 1-D RCE model, konrad.

Financial support. This research has been supported by the Deutsche Forschungsgemeinschaft (DFG) Research Unit VolImpact (FOR2820; grant no. 398006378) within the projects VolDyn and VolClim.

35

The article processing charges for this open-access publication were covered by the Max Planck Society.

Review statement. This paper was edited by Slimane Bekki and reviewed by two anonymous referees.

\section{${ }_{40}$ References}

Angell, J. K.: Stratospheric warming due to Agung, El Chichón, and Pinatubo taking into account the quasi- biennial oscillation, J. Geophys. Res.-Atmos., 102, 9479-9485, https://doi.org/10.1029/96JD03588, 1997.

Azoulay, A., Schmidt, H., and Timmreck, C.: The Arctic polar 45 vortex response to volcanic forcing of different strengths, J. Geophys. Res., submitted, further information available at: http://hdl.handle.net/21.11116/0000-0007-8B38-E (last access: 20 November 2020), 2021 (primary data available at: https://pure.mpg.de/pubman/item/item_3270673_8/component/ 50 file_3314921/JGR-D_Azoulay-2021.tar.gz?mode=download, last access: 13 September 2019).

Bekki, S.: Oxidation of volcanic $\mathrm{SO}_{2}$ : A sink for stratospheric $\mathrm{OH}$ and $\mathrm{H}_{2} \mathrm{O}$, Geophys. Res. Lett., 22, 913-916, https://doi.org/10.1029/95GL00534, 1995.

Boucher, O., Kleinschmitt, C., and Myhre, G.: Quasi-Additivity of the Radiative Effects of Marine Cloud Brightening and Stratospheric Sulfate Aerosol Injection, Geophys. Res. Lett., 44, 11158-11165, https://doi.org/10.1002/2017GL074647, 2017.

Brewer, A. W.: Evidence for a world circulation provided by 60 the measurements of helium and water vapour distribution in the stratosphere, Q. J. Roy. Meteor. Soc., 75, 351-363, https://doi.org/10.1002/qj.49707532603, 1949.

Case, P. A., Tsigaridis, K., and LeGrande, A. N.: The Effect of Stratospheric Water Vapor in Large Volcanic Eruptions on Cli- 65 mate and Atmospheric Composition, in: AGU Fall Meeting, San Fracisco, California, 14-18 December 2015, A51N-0270, AGU, available at: https://agu.confex.com/agu/fm15/meetingapp.cgi/ Paper/79947 (last access: 13 September 2020), 2015.

Coffey, M. T.: Observations of the impact of volcanic activity on 70 stratospheric chemistry, J. Geophys. Res.-Atmos., 101, 67676780, 1996.

Dacie, S., Kluft, L., Schmidt, H., Stevens, B., Buehler, S. A., Nowack, P. J., Dietmüller, S., Abraham, N. L., and Birner, T.: A 1D RCE Study of Factors Affecting the Tropical 7 Tropopause Layer and Surface Climate, J. Climate, 32, 67696782, https://doi.org/10.1175/JCLI-D-18-0778.1, 2019.

Davis, S. M., Hegglin, M. I., Fujiwara, M., Dragani, R., Harada, Y., Kobayashi, C., Long, C., Manney, G. L., Nash, E. R., Potter, G. L., Tegtmeier, S., Wang, T., Wargan, K., and Wright, J. 80 S.: Assessment of upper tropospheric and stratospheric water vapor and ozone in reanalyses as part of S-RIP, Atmos. Chem. Phys., 17, 12743-12778, https://doi.org/10.5194/acp-17-127432017, 2017.

Dee, D. P., Uppala, S. M., Simmons, A. J., Berrisford, P., Poli, 85 P., Kobayashi, S., Andrae, U., Balmaseda, M. A., Balsamo, G., Bauer, P., Bechtold, P., Beljaars, A. C. M., van de Berg, L., Bidlot, J., Bormann, N., Delsol, C., Dragani, R., Fuentes, M., Geer, A. J., Haimberger, L., Healy, S. B., Hersbach, H., Hólm, E. V., Isaksen, L., Kållberg, P., Köhler, M., Matricardi, M., McNally, 9 A. P., Monge-Sanz, B. M., Morcrette, J.-J., Park, B.-K., Peubey, C., de Rosnay, P., Tavolato, C., Thépaut, J.-N., and Vitart, F.: The ERA-Interim reanalysis: configuration and performance of the data assimilation system, Q. J. Roy. Meteor. Soc., 137, 553-597, https://doi.org/10.1002/qj.828, 2011.

Dessler, A. E., Schoeberl, M. R., Wang, T., Davis, S. M., and Rosenlof, K. H.: Stratospheric water vapor feedback, P. Natl. Acad. Sci. USA, 110, 18087-18091, https://doi.org/10.1073/pnas.1310344110, 2013.

Dessler, A. E., Schoeberl, M. R., Wang, T., Davis, S. M., Rosenlof, 100 K. H., and Vernier, J.-P.: Variations of stratospheric water va- 
por over the past three decades, J. Geophys. Res.-Atmos., 119, 12588-12598, https://doi.org/10.1002/2014JD021712, 2014.

Diallo, M., Ploeger, F., Konopka, P., Birner, T., Müller, R., Riese, M., Garny, H., Legras, B., Ray, E., Berthet, G., and Jegou, F.: Significant Contributions of Volcanic Aerosols to Decadal Changes in the Stratospheric Circulation, Geophys. Res. Lett., 44, 10780 10791, https://doi.org/10.1002/2017GL074662, 2017.

Driscoll, S., Bozzo, A., Gray, L. J., Robock, A., and Stenchikov, G.: Coupled Model Intercomparison Project 5 (CMIP5) simula-

10 tions of climate following volcanic eruptions, J. Geophys. Res.Atmos., 117, D17105, https://doi.org/10.1029/2012JD017607, 2012

Fels, S. B., Mahlman, J., Schwarzkopf, M., and Sinclair, R.: Stratospheric Sensitivity to Perturbations in Ozone and Carbon

15 Dioxide: Radiative and Dynamical Response, Journal of Atmospheric Sciences, 37, 2265-2297, https://doi.org/10.1175/15200469(1980)037<2265:SSTPIO>2.0.CO;2, 1980.

Forster, P. M., Richardson, T., Maycock, A. C., Christopher J. Smith, C. J., Samset, B. H., Myhre, G., Timothy An-

20 drews, Timothy Pincus, R., and Schulz, M.: Recommendations for diagnosing effective radiative forcing from climate models for CMIP6, J. Geophys. Res.-Atmos., 121, 12460-12475, https://doi.org/10.1002/2016JD025320, 2016.

Forster, P. M. d. F. and Shine, K. P.: Assessing the climate impact

25 of trends in stratospheric water vapor, Geophys. Res. Lett., 29, 10-1-10-4, https://doi.org/10.1029/2001GL013909, 2002.

Fueglistaler, S., Dessler, A. E., Dunkerton, T. J., Folkins, I., Fu, Q., and Mote, P. W.: Tropical tropopause layer, Rev. Geophys., 47, 1606, https://doi.org/10.1029/2008RG000267, 2009.

so Fueglistaler, S., Liu, Y. S., Flannaghan, T. J., Haynes, P. H., Dee, D. P., Read, W. J., Remsberg, E. E., Thomason, L. W., Hurst, D. F., Lanzante, J. R., and Bernath, P. F.: The relation between atmospheric humidity and temperature trends for stratospheric water, J. Geophys. Res.-Atmos., 118, 1052-1074,

35 https://doi.org/10.1002/jgrd.50157, 2013.

Fujiwara, M., Wright, J. S., Manney, G. L., Gray, L. J., Anstey, J., Birner, T., Davis, S., Gerber, E. P., Harvey, V. L., Hegglin, M. I., Homeyer, C. R., Knox, J. A., Krüger, K., Lambert, A., Long, C. S., Martineau, P., Molod, A., Monge-Sanz, B. M., Santee, M. L., Tegtmeier, S., Chabrillat, S., Tan, D. G. H., Jackson, D. R., Polavarapu, S., Compo, G. P., Dragani, R., Ebisuzaki, W., Harada, Y., Kobayashi, C., McCarty, W., Onogi, K., Pawson, S., Simmons, A., Wargan, K., Whitaker, J. S., and Zou, C.-Z.: Introduction to the SPARC Reanalysis Intercomparison Project (S-RIP) and overview of the reanalysis systems, Atmos. Chem. Phys., 17, 1417-1452, https://doi.org/10.5194/acp17-1417-2017, 2017.

Gelaro, R., McCarty, W., Suárez, M. J., Todling, R., Molod, A., Takacs, L., Randles, C., Darmenov, A., Bosilovich, M. G., Re-

50 ichle, R., Wargan, K., Coy, L., Cullather, R., Draper, C., Akella, S., Buchard, V., Conaty, A., da Silva, A., Gu, W., Kim, G.-K., Koster, R., Lucchesi, R., Merkova, D., Nielsen, J. E., Partyka, G., Pawson, S., Putman, W., Rienecker, M., Schubert, S. D., Sienkiewicz, M., and Zhao, B.: The Modern-Era Retrospective 5 Analysis for Research and Applications, Version 2 (MERRA-2), J. Climate, 30, 5419-5454, https://doi.org/10.1175/JCLI-D-160758.1, 2017.

Giorgetta, M. A., Jungclaus, J., Reick, C. H., Legutke, S., Bader, J., Böttinger, M., Brovkin, V., Crueger, T., Esch, M., Fieg, K.,
Glushak, K., Gayler, V., Haak, H., Hollweg, H.-D., Ilyina, T., 60 Kinne, S., Kornblueh, L., Matei, D., Mauritsen, T., Mikolajewicz, U., Mueller, W., Notz, D., Pithan, F., Raddatz, T., Rast, S., Redler, R., Roeckner, E., Schmidt, H., Schnur, R., Segschneider, J., Six, K. D., Stockhause, M., Timmreck, C., Wegner, J., Widmann, H., Wieners, K.-H., Claussen, M., Marotzke, J., and 6 Stevens, B.: Climate and carbon cycle changes from 1850 to 2100 in MPI-ESM simulations for the Coupled Model Intercomparison Project phase 5, J. Adv. Model. Earth Sy., 5, 572-597, https://doi.org/10.1002/jame.20038, 2013.

Glaze, L. S., Baloga, S. M., and Wilson, L.: Trans- 70 port of atmospheric water vapor by volcanic eruption columns, J. Geophys. Res.-Atmos., 102, 6099-6108, https://doi.org/10.1029/96JD03125, 1997.

Hall, T. M. and Waugh, D.: Tracer transport in the tropical stratosphere due to vertical diffusion and horizontal mixing, Geophys. 75 Res. Lett., 24, 1383-1386, https://doi.org/10.1029/97GL01289, 1997.

Hansen, J., Sato, M., Ruedy, R., Nazarenko, L., Lacis, A., Schmidt, G. A., Russell, G., Aleinov, I., Bauer, M., Bauer, S., Bell, N., Cairns, B., Canuto, V., Chandler, M., Cheng, Y., Del Genio, A., Faluvegi, G., Fleming, E., Friend, A., Hall, T., Jackman, C., Kelley, M., Kiang, N., Koch, D., Lean, J., Lerner, J., Lo, K., Menon, S., Miller, R., Minnis, P., Novakov, T., Oinas, V., Perlwitz, J., Perlwitz, J., Rind, D., Romanou, A., Shindell, D., Stone, P., Sun, S., Tausnev, N., Thresher, D., Wielicki, B., Wong, T., Yao, M., 85 and Zhang, S.: Efficacy of climate forcings, J. Geophys. Res.Atmos., 110, D18104, https://doi.org/10.1029/2005JD005776, 2005.

Huang, Y., Wang, Y., and Huang, H.: Stratospheric Water Vapor Feedback Disclosed by a Locking Ex- 90 periment, Geophys. Res. Lett., 47, e2020GL087987, https://doi.org/10.1029/2020GL087987, 2020.

Ilyina, T., Six, K. D., Segschneider, J., Maier-Reimer, E., Li, H., and Núñez-Riboni, I.: Global ocean biogeochemistry model HAMOCC: Model architecture and performance as compo- 9 nent of the MPI-Earth system model in different CMIP5 experimental realizations, J. Adv. Model. Earth Sy., 5, 287-315, https://doi.org/10.1029/2012MS000178, 2013.

Joshi, M. M. and Jones, G. S.: The climatic effects of the direct injection of water vapour into the stratosphere by 100 large volcanic eruptions, Atmos. Chem. Phys., 9, 6109-6118, https://doi.org/10.5194/acp-9-6109-2009, 2009.

Joshi, M. M. and Shine, K. P.: A GCM Study of Volcanic Eruptions as a Cause of Increased Stratospheric Water Vapor, J. Climate, 16, 3525-3534, https://doi.org/10.1175/1520- 105 0442(2003)016<3525:AGSOVE >2.0.CO;2, 2003.

Jungclaus, J. H., Fischer, N., Haak, H., Lohmann, K., Marotzke, J., Matei, D., Mikolajewicz, U., Notz, D., and von Storch, J. S.: Characteristics of the ocean simulations in the Max Planck Institute Ocean Model (MPIOM) the ocean component of the MPI- 110 Earth system model, J. Adv. Model. Earth Sy., 5, 422-446, https://doi.org/10.1002/jame.20023, 2013.

Kilian, M., Brinkop, S., and Jöckel, P.: Impact of the eruption of Mt Pinatubo on the chemical composition of the stratosphere, Atmos. Chem. Phys., 20, 11697-11715, 115 https://doi.org/10.5194/acp-20-11697-2020, 2020. 
Kluft, L. and Dacie, S.: atmtools/konrad: A radiativeconvective equilibrium model for Python, Zenodo [data set], https://doi.org/10.5281/zenodo.2597967, 2019.

Kluft, L., Dacie, S., Buehler, S. A., Schmidt, H., and Stevens,

5 B.: Re-Examining the First Climate Models: Climate Sensitivity of a Modern Radiative-Convective Equilibrium Model, J. Climate, 32, 8111-8125, https://doi.org/10.1175/JCLI-D-180774.1, 2019.

Kobayashi, S., Ota, Y., Harada, Y., Ebita, A., Miyaoka, M., Onoda,

10 H., Onogi, K., Kamahori, H., Kobayashi, C., Endo, H., Miyaoka, K., and Takahshini, K.: The JRA-55 Reanalysis: General Specifications and Basic Characteristics, J. Meteorol. Soc. Jpn. Ser. II, 93, 5-48, https://doi.org/10.2151/jmsj.2015-001, 2015.

Krishnamohan, K.-P. S.-P., Bala, G., Cao, L., Duan, L., and

15 Caldeira, K.: Climate system response to stratospheric sulfate aerosols: sensitivity to altitude of aerosol layer, Earth Syst. Dynam., 10, 885-900, https://doi.org/10.5194/esd-10-885-2019, 2019.

Kroll, C. A.: Supplementary Material to "The impact of volcanic

20 eruptions of different magnitude on stratospheric water vapour in the tropics", available at: https://pure.mpg.de/pubman/faces/ ViewItemOverviewPage.jsp?itemId=item_3270686, last access: 20 November 2020.

LeGrande, A. N., Tsigaridis, K., and Bauer, S. E.: Role of

25 atmospheric chemistry in the climate impacts of stratospheric volcanic injections, Nat. Geosci., 9, 652-655, https://doi.org/10.1038/ngeo2771, 2016.

Löffler, M., Brinkop, S., and Jöckel, P.: Impact of major volcanic eruptions on stratospheric water vapour, Atmos.

so Chem. Phys., 16, 6547-6562, https://doi.org/10.5194/acp-166547-2016, 2016.

Maher, N., Milinski, S., Suarez-Gutierrez, L., Botzet, M., Dobrynin, M., Kornblueh, L., Kröger, J., Takano, Y., Ghosh, R., Hedemann, C., Li, C., Li, H., Manzini, E., Notz, D., Putrasahan,

35 D., Boysen, L., Claussen, M., Ilyina, T., Olonscheck, D., Raddatz, T., Stevens, B., and Marotzke, J.: The Max Planck Institute Grand Ensemble: Enabling the Exploration of Climate System Variability, J. Adv. Model. Earth Sy., 11, 2050-2069, https://doi.org/10.1029/2019MS001639, 2019.

40 Marshall, L., Schmidt, A., Toohey, M., Carslaw, K. S., Mann, G. W., Sigl, M., Khodri, M., Timmreck, C., Zanchettin, D., Ball, W. T., Bekki, S., Brooke, J. S. A., Dhomse, S., Johnson, C., Lamarque, J.-F., LeGrande, A. N., Mills, M. J., Niemeier, U., Pope, J. O., Poulain, V., Robock, A., Rozanov, E., Stenke, A., Sukhodolov,

45 T., Tilmes, S., Tsigaridis, K., and Tummon, F.: Multi-model comparison of the volcanic sulfate deposition from the 1815 eruption of Mt. Tambora, Atmos. Chem. Phys., 18, 2307-2328, https://doi.org/10.5194/acp-18-2307-2018, 2018.

Marsland, S. J., Haak, H., Jungclaus, J. H., Latif, M., and Röske,

50 F.: The Max-Planck-Institute global ocean/sea ice model with orthogonal curvilinear coordinates, Ocean Model., 5, 91-127, https://doi.org/10.1016/S1463-5003(02)00015-X, 2003.

Mauritsen, T., Bader, J., Becker, T., Behrens, J., Bittner, M., Brokopf, R., Brovkin, V., Claussen, M., Crueger, T., Esch, M.,

${ }_{55}$ Fast, I., Fiedler, S., Fläschner, D., Gayler, V., Giorgetta, M., Goll, D. S., Haak, H., Hagemann, S., Hedemann, C., Hohenegger, C., Ilyina, T., Jahns, T., Jimenéz-de-la Cuesta, D., Jungclaus, J., Kleinen, T., Kloster, S., Kracher, D., Kinne, S., Kleberg, D., Lasslop, G., Kornblueh, L., Marotzke, J., Matei, D., Meraner, K.,
Mikolajewicz, U., Modali, K., Möbis, B., Müller, W. A., Nabel, 60 J. E. M. S., Nam, C. C. W., Notz, D., Nyawira, S.-S., Paulsen, H., Peters, K., Pincus, R., Pohlmann, H., Pongratz, J., Popp, M., Raddatz, T. J., Rast, S., Redler, R., Reick, C. H., Rohrschneider, T., Schemann, V., Schmidt, H., Schnur, R., Schulzweida, U., Six, K. D., Stein, L., Stemmler, I., Stevens, B., Storch, J.S., Tian, F., Voigt, A., Vrese, P., Wieners, K.-H., Wilkenskjeld, S., Winkler, A., and Roeckner, E.: Developments in the MPIM Earth System Model version 1.2 (MPI-ESM1.2) and Its Response to Increasing $\mathrm{CO}_{2}$, J. Adv. Model. Earth Sy., 11, 9981038, https://doi.org/10.1029/2018MS001400, 2019.

Möbis, B. and Stevens, B.: Factors controlling the position of the Intertropical Convergence Zone on an aquaplanet, J. Adv. Model. Earth Sy., 4, https://doi.org/10.1029/2012MS000199, 2012.

Mote, P. W., Rosenlof, K. H., McIntyre, M. E., Carr, E. S., Gille, J. C., Holton, J. R., Kinnersley, J. S., Pumphrey, H. C., Rus- 75 sell, J. M., and Waters, J. W.: An atmospheric tape recorder: The imprint of tropical tropopause temperatures on stratospheric water vapor, J. Geophys. Res.-Atmos., 101, 3989-4006, https://doi.org/10.1029/95JD03422, 1996.

Murcray, D. G., Murcray, F. J., Barker, D. B., and Mastenbrook, 80 H. J.: Changes in stratospheric water vapor associated with the mount St. Helens eruption, Science (New York, N. Y.), 211, 823824, https://doi.org/10.1126/science.211.4484.823, 1981.

Murphy, D. M. and Koop, T.: Review of the vapour pressures of ice and supercooled water for atmospheric applications, Q. J. Roy. 85 Meteor. Soc., 131, 1539-1565, https://doi.org/10.1256/qj.04.94, 2005.

Myhre, G., Shindell, D., Bréon, F.-M., Collins, W., Fuglestvedt, J., Huang, J., Koch, D., Lamarque, J.-F., Lee, D., Mendoza, B., Nakajima, T., Robock, A., Stephens, G., Takemura, T., 90 and Zhang, H.: Anthropogenic and Natural Radiative Forcing, in: Climate Change 2013: The Physical Science Basis. Contribution of Working Group I to the Fifth Assessment Report of the Intergovernmental Panel of Climate Change, available at: https://www.ipcc.ch/site/assets/uploads/2018/02/WG1AR5_ Chapter08_FINAL.pdf (last access: 10 June 2020), 2013.

Oltmans, S., Voemel, H., Kley, D., Hofmann, K. P., and Rosenlof, $\mathrm{K}$.: Increase in stratospheric water vapor from balloon-borne, frostpoint hygrometer measurements at Washington, DC and Boulder, Colorado, Geophys. Res. Lett., 27, 3453-3456, 2000. 100

Oman, L., Waugh, D. W., Pawson, S., Stolarski, R. S., and Nielsen, J. E.: Understanding the Changes of Stratospheric Water Vapor in Coupled Chemistry Climate Model Simulations, J. Atmos. Sci., 65, 3278-3291, https://doi.org/10.1175/2008JAS2696.1, 2008.

Reick, C. H., Raddatz, T., Brovkin, V., and Gayler, V.: Rep- 105 resentation of natural and anthropogenic land cover change in MPI-ESM, J. Adv. Model. Earth Sy., 5, 459-482, https://doi.org/10.1002/jame.20022, 2013.

Rienecker, M. M., Suarez, M. J., Gelaro, R., Todling, R., Bacmeister, J., Liu, E., Bosilovich, M. G., Schubert, S. D., Takacs, L., 110 Kim, G.-K., Bloom, S., Chen, J., Collins, D., Conaty, A., da Silva, A., Gu, W., Joiner, J., Koster, R. D., Lucchesi, R., Molod, A., Owens, T., Pawson, S., Pegion, P., Redder, C. R., Reichle, R., Robertson, F. R., Ruddick, A. G., Sienkiewicz, M., and Woollen, J.: MERRA: NASA's Modern-Era Retrospective Anal- 115 ysis for Research and Applications, J. Climate, 24, 3624-3648, https://doi.org/10.1175/JCLI-D-11-00015.1, 2011. 
Robock, A.: Volcanic eruptions and climate, Rev. Geophys., 38, 191-219, https://doi.org/10.1029/1998RG000054, 2000.

Robrecht, S., Vogel, B., Grooß, J.-U., Rosenlof, K., Thornberry, T., Rollins, A., Krämer, M., Christensen, L., and Müller, R.:

5 Mechanism of ozone loss under enhanced water vapour conditions in the mid-latitude lower stratosphere in summer, Atmos. Chem. Phys., 19, 5805-5833, https://doi.org/10.5194/acp19-5805-2019, 2019.

Rosenlof, K. H.: Changes in water vapor and aerosols and their

10 relation to stratospheric ozone, C. R. Geosci., 350, 376-383, https://doi.org/10.1016/j.crte.2018.06.014, 2018.

Rosenlof, K. H., Oltmans, S. J., Kley, D., Russell, J. M., Chiou, E.-W., Chu, W. P., Johnson, D. G., Kelly, K. K., Michelsen, H. A., Nedoluha, G. E., Remsberg, E. E., Toon, G. C., and

15 McCormick, M. P.: Stratospheric water vapor increases over the past half-century, Geophys. Res. Lett., 28, 1195-1198, https://doi.org/10.1029/2000GL012502, 2001.

Santer, B. D., Sausen, R., Wigley, T. M. L., Boyle, J. S., AchutaRao, K., Doutriaux, C., Hansen, J. E., Meehl, G. A.,

20 Roeckner, E., Ruedy, R., Schmidt, G., and Taylor, K. E.: Behavior of tropopause height and atmospheric temperature in models, reanalyses, and observations: Decadal changes, J. Geophys. Res.-Atmos., 108, ACL 1-1-ACL 1-22, https://doi.org/10.1029/2002JD002258, 2003.

${ }_{25}$ Schmidt, H., Rast, S., Bunzel, F., Esch, M., Giorgetta, M., Kinne, S., Krismer, T., Stenchikov, G., Timmreck, C., Tomassini, L., and Walz, M.: Response of the middle atmosphere to anthropogenic and natural forcings in the CMIP5 simulations with the Max Planck Institute Earth system model, J. Adv. Model. Earth Sy.,

$30 \quad$ 5, 98-116, https://doi.org/10.1002/jame.20014, 2013.

Schneck, R., Reick, C. H., and Raddatz, T.: Land contribution to natural $\mathrm{CO}_{2}$ variability on time scales of centuries, J. Adv. Model. Earth Sy., 5, 354-365, https://doi.org/10.1002/jame.20029, 2013.

${ }_{35}$ Schoeberl, M. R. and Dessler, A. E.: Dehydration of the stratosphere, Atmos. Chem. Phys., 11, 8433-8446, https://doi.org/10.5194/acp-11-8433-2011, 2011.

Schwartz, M. J., Read, W. G., Santee, M. L., Livesey, N. J., Froidevaux, L., Lambert, A., and Manney, G. L.: Convectively injected water vapor in the North American summer lowermost stratosphere, Geophys. Res. Lett., 40, 2316-2321, https://doi.org/10.1002/grl.50421, 2013.

Sioris, C. E., Malo, A., McLinden, C. A., and D'Amours, R.: Direct injection of water vapor into the stratosphere

45 by volcanic eruptions, Geophys. Res. Lett., 43, 7694-7700, https://doi.org/10.1002/2016GL069918, 2016a.
Sioris, C. E., Zou, J., McElroy, C. T., Boone, C. D., Sheese, P. E., and Bernath, P. F.: Water vapour variability in the high-latitude upper troposphere - Part 2: Impact of volcanic eruptions, Atmos. Chem. Phys., 16, 2207-2219, https://doi.org/10.5194/acp- 50 16-2207-2016, 2016b.

Soden, B. J., Wetherald, R. T., Stenchikov, G. L., and Robock, A.: Global cooling after the eruption of Mount Pinatubo: a test of climate feedback by water vapor, Science (New York, N. Y.), 296, 727-730, https://doi.org/10.1126/science.296.5568.727, 2002.

Solomon, S., Rosenlof, K. H., Portmann, R. W., Daniel, J. S., Davis, S. M., Sanford, T. J., and Plattner, G.-K.: Contributions of stratospheric water vapor to decadal changes in the rate of global warming, Science (New York, N. Y.), 327, 1219-1223, https://doi.org/10.1126/science.1182488, 2010.

Stenchikov, G. L., Kirchner, I., Robock, A., Graf, H.-F., Antuña, J. C., Grainger, R. G., Lambert, A., and Thomason, L.: Radiative forcing from the 1991 Mount Pinatubo volcanic eruption, J. Geophys. Res.-Atmos., 103, 13837-13857, https://doi.org/10.1029/98JD00693, 1998.

Stevens, B. and Bony, S.: Water in the atmosphere, Phys. Today, 66 , 29-34, https://doi.org/10.1063/PT.3.2009, 2013.

Tao, M., Konopka, P., Ploeger, F., Yan, X., Wright, J. S., Diallo, M., Fueglistaler, S., and Riese, M.: Multitimescale variations in modeled stratospheric water vapor derived from three modern reanalysis products, Atmos. Chem. Phys., 19, 6509-6534, https://doi.org/10.5194/acp-19-6509-2019, 2019.

Tian, W., Chipperfield, M. P., and Lü, D.: Impact of increasing stratospheric water vapor on ozone depletion and temperature change, Adv. Atmos. Sci., 26, 423-437, 75 https://doi.org/10.1007/s00376-009-0423-3, 2009.

Timmreck, C., Mann, G. W., Aquila, V., Hommel, R., Lee, L. A., Schmidt, A., Brühl, C., Carn, S., Chin, M., Dhomse, S. S., Diehl, T., English, J. M., Mills, M. J., Neely, R., Sheng, J., Toohey, M., and Weisenstein, D.: The Interactive Stratospheric Aerosol Model Intercomparison Project (ISA-MIP): motivation and experimental design, Geosci. Model Dev., 11, 2581-2608, https://doi.org/10.5194/gmd-11-2581-2018, 2018.

Toohey, M., Stevens, B., Schmidt, H., and Timmreck, C.: Easy Volcanic Aerosol (EVA v1.0): an idealized forcing generator 8 for climate simulations, Geosci. Model Dev., 9, 4049-4070, https://doi.org/10.5194/gmd-9-4049-2016, 2016.

Wang, T., Zhang, Q., Kuilman, M., and Hannachi, A.: Response of stratospheric water vapour to $\mathrm{CO}_{2}$ doubling in WACCM, Clim. Dynam., 54, 4877-4889, https://doi.org/10.1007/s00382- 90 020-05260-z, 2020. 